Working Papers

\title{
Utilizing financial market information in forecasting real growth, inflation and real exchange rate
}

\author{
Juha Junttila \\ University of Oulu \\ and \\ Marko Korhonen \\ University of Turku
}

Working Paper No. 0801

January 2008

ISSN 1796-7961 
Department of Economics

University of Oulu

Working Paper No. 0801

\title{
Utilizing financial market information in forecasting real growth, inflation and real exchange rate*
}

\begin{abstract}
Building on an extension of the Gordon (1962) growth model we propose a simple approach to forecasting real growth, inflation and real exchange rate. This extension is rooted in introducing the Fisher (1930) and Euler equations, and in the open economy context, also the purchasing power parity (PPP) and the uncovered interest rate parity (UIP) relations to the analysis. These equilibrium conditions suggest a forecasting system of three simple equations, all based on current financial market information in the form of dividend yields and short-term interest rate. Our empirical results indicate that the role of simple financial market information both in the forms of dividend yields and nominal interest rate is relevant for forecasting out-of-sample the time-varying underlying trends in the macroeconomic data for the U.K., Euro-zone and Japan, when treating the U.S. as the world market. Our results strongly stress the importance of including some measure of stock market performance in macroeconomic forecasting systems, especially during turbulent time periods in financial markets and macro economy.
\end{abstract}

JEL Classification: G15, G28.

Keywords: Stock market, forecasting, macro economy, exchange rates

Juha Junttila

Department of Economics

University of Oulu

P.O.Box 4600

FIN-90014 University of Oulu

FINLAND

e-mail: juha.junttila@oulu.fi
Marko Korhonen

Department of Economics

University of Turku

Assistentinkatu 7

FIN-20014 Turku

FINLAND

e-mail:mjkorho@utu.fi

* An earlier version of this paper was titled 'An augmented Gordon model for forecasting macroeconomic variables' and we thank Louis K. C. Chan, Juha Tarkka and Mikko Puhakka for their comments and suggestions for that version, and the more recent modifications of it. Junttila is also grateful for the financial support from the OKO-Bank of Finland and the Yrjö Jahnsson Foundation, and for the hospitality of the Bank of Finland Research Department during his ancient visit to the Bank in 2001, which, in addition to some other research papers, launched also this research project. Finally, thanks to Juha Joenväärä and Jukka Pakola for their help with some data issues. 


\section{Introduction}

The recently increased possibility of significant downturn in economic activity in the near future has intensified research on the connections between the financial market and macroeconomic performance. The roots of these concerns are once again in the alarming short-term behavior of the financial market prices and returns. It is clear that even though the aggregate stock market indexes like the S\&P 500 for the U.S. market and S\&P 350 for the Euro market have experienced for decades a clearly positive long-run (e.g., 5year) trend, even fairly short-term (e.g., from 3 to 6 months) periods of decreasing stock market indexes are always worrying for the financial market practitioners and policy makers, in view of their potential real economy effects.

For example the study by Stock and Watson (2003) lays good ground for the empirical analysis of the role of financial market prices and/or returns in forecasting macro economy. The basic idea in all the analyses in this area ${ }^{1}$ is the fact that asset prices are forward-looking, and they form a class of potentially useful predictors of future values of macroeconomic indicators like output growth and inflation. Stock and Watson also argue that actually the role of asset prices in forecasting future aggregate economic conditions is basically rooted in some fairly simple foundational macroeconomic concepts. Among these are the theory by Irving Fisher stating that the nominal interest rate is comprised of real interest rate plus expected inflation, and the hypothesis that stock prices reflect the expected present discounted value of stock market fundamentals, e.g., future earnings or dividends ${ }^{2}$. However, the general finding from the studies on macro forecasting using several types of financial data sets is that it seems to be the case that some data forecast some macro variables in some countries for some time periods, but the sets of relevant forecasting financial data collections vary a lot between countries and time periods (see Stock and Watson (2003).

In addition to building a forecasting framework which utilizes simple stock market information for real growth and inflation, we also want to contribute to another fairly new area of research focusing on the connection between the stock market and currency

\footnotetext{
${ }^{1}$ Based on their own studies and a huge number of studies by other researchers Stock and Watson (2003) give an extensive review on the possibilities of sets of different kinds of financial market and other economic indicators that might have a role to play in forecasting especially the values of economic growth and inflation. However, in this paper we want to focus especially on the role of simple stock market information. Another comprehensive review on these issues is provided by Cochrane (2006) in his collection of some of the most essential articles on our theme. Other recent papers focusing especially on real growth and inflation forecasting in the U.S. and Euro area are for example Banerjee and Marcellino (2006) and Marcellino, Stock and Watson (2003).

${ }^{2}$ For an early practical implementation of this latter idea, see Mitchell and Burns (1938).
} 
market. A short list of some of the most interesting recent innovative papers in this area includes Ehrmann, Fratzscher and Rigobon (2005), Phylaktis and Ravazzolo (2005), Hau and Rey (2004 and 2006), Francis, Hasan and Hunter (2006), Andersen, Bollerslev, Diebold and Vega (2007), and Pavlova and Rigobon (2007).

Ehrmann et al. (2005) analyze the degree of financial transmission between money, bond, equity and currency markets between the United States and the Euro area. They find strong international spillover effects, both within asset classes as well as across financial markets. They also report that the direct transmission of financial shocks within asset classes is strengthened through indirect spillovers via other asset prices. These results call for a better understanding of international cross-market financial linkages, which so far has been missing in the literature. Phylaktis and Ravazzolo (2005) use a data set of a group of Pacific Basin countries over 1980 - 1998 and analyze it with cointegration and VAR models. They find evidence of positive correlation between foreign exchange and stock markets and that the U.S. stock market acts as a conduit through which the foreign exchange and the local stock markets are linked. Furthermore, in these countries for example the foreign exchange restrictions were not a determinant of the link between the domestic stock and foreign exchange markets on the one hand, and between the domestic capital and world capital markets on the other hand.

For the part of exchange rate vs. stock market discussion perhaps the most intriguing recent papers for our analysis are the ones by Hau and Rey (2004 and 2006). In their 2004 paper they introduce three main hypotheses for this relationship, based on the portfolio rebalancing effects presented by Kouri (1982) and Branson and Henderson (1985). According to their first hypothesis foreign equity market appreciations relative to the home equity market induce a portfolio rebalancing effect in the form of home investor's reductions of foreign equity holdings for the purpose of reducing her exchange-rate risk exposure. This results in foreign-equity outflows and a home currency appreciation. Their second hypothesis states that if the foreign currency appreciates, it increases the home currency share of assets in the foreign market and the higher overall foreign exchange rate risk exposure for the home residents may induce foreign equity market outflows, and the foreign outflows should produce negative foreign-equity excess returns, when returns are measured in local currency. The third hypothesis states that the equity-flow innovations change the demand for currency balances and for equity. Foreign equity market inflows appreciate the foreign currency relative to home currency and induce excess returns in the foreign equity. All these hypotheses gain support from their 
empirical analysis using monthly portfolio flow data for the period of January 1990 September 2003 from France, Germany, Japan, Switzerland, and U.K., and treating the U.S. as the home country. However, the low-frequency nature of the portfolio flow data and the inclusion of two price variables (exchange rate and the stock price(s)) in the VAR representations of the data appear inconsistent with any particular causal ordering, so the direction of causality between the two markets remains more or less an unsolved question.

Hau and Rey (2006) build an equilibrium model where exchange rates, stock prices and capital flows are jointly determined under incomplete foreign exchange risk trading, is under scrutiny. Their thorough empirical analysis uses daily, monthly, and quarterly stock index and exchange rate data for 17 OECD countries, always relative to the U.S, mainly for the period from the beginning of 1980 until the end of 2001. They find strong evidence that there is a negative correlation between the excess returns on foreign over the U.S. equity and returns on the foreign currency as predicted by their equilibrium model. Hence, both their theoretical model and empirical results contradict the previous conventional wisdom that a strong equity market is connected to strong currency. Furthermore, the negative correlation would seem to be the strongest for the post-1990 period, when equity markets became more open. These results are also confirmed from using monthly equity flow data on the same OECD countries, revealing a positive correlation between equity flows into foreign market and the appreciation of the foreign currency.

Also Francis et al. (2006) use flow data in their analysis, but in the form of currency market order flow. They utilize a trivariate asymmetric GARCH approach to model the dynamic relationships between equity and currency markets in a data set comprising of Canada, Germany, Japan and the U.K., and treating again the U.S. as the home market. Their main hypothesis is that spillovers between the currency market and domestic and foreign equity markets are due to information flow, and they posit that unexpected currency order flow is the vehicle that transmits information among these markets. Indeed, in the empirical part they find significant, bidirectional mean and volatility spillovers between currency and equity markets and between U.S. and foreign equity markets. Furthermore, because they allow the endogeneity of the exchange rate in the analysis, they are able to find that the spillover from changes in exchange rate to equity returns is greatest when both the exchange rate and the associated foreign equity returns are endogenous variables in the system. Hence, they argue that the finding of strong 
dynamic relationships between currency returns and equity markets indicates that the results from some previous studies (e.g., Hamao et al. (1990) and Susmel and Engle (1994)) treating either the currency or equity markets as exogenous are perhaps misspecified.

Finally, Andersen et al. (2007) and Pavlova and Rigobon (2007) are some of the most recent papers connecting explicitly also the role of macro economy to the analysis of the relationship between the currency and stock markets. Perhaps more remotely connected to our analysis, Andersen et al. use a high-frequency futures dataset to characterize the response of U.S., German and British stock, bond and foreign exchange markets to realtime U.S. macroeconomic news, and find the stock, bond and exchange rate dynamics to be linked to macroeconomic fundamentals. However, especially the equity market reaction seems to be dependent on the business cycle conditions and actually, when conditioning on the state of the economy, the equity and foreign exchange rate markets appear equally responsive to macro news than the bond market. They also find strong contemporaneous connection across all the analyzed markets and countries even after controlling for the effects of macroeconomic news. Instead of analyzing simply the dependence of the returns from different markets, Pavlova and Rigobon (2007) derive a closed-form solution for a model describing the connections between stock, bond and foreign exchange markets. This enables them to study the implications of introducing demand shocks and trade in goods into an otherwise standard international asset pricing model. In their model trade in goods is the key variable enabling the channel of international propagation through the terms of trade that is absent in the traditional single-good models. Using monthly macro data and daily financial data for the U.S. and the U.K. during 1988 - 2002, in the empirical part they find that demand shocks are twice as important as supply shocks in describing the behavior of asset prices and exchange rates. At the final stage of the paper they analyze the out-of-sample performance of the supply and demand factors in predicting several macroeconomic variables and find that these latent factors are able to predict for example the fluctuations in industrial production both in the U.S. and the U.K.

This paper contributes to both 'branches' of macro forecasting and of financial market connections to currency market literature. We propose a model which includes many of the insights from the above papers in a somewhat compact way. We start from basic macroeconomic equilibrium conditions mentioned, but not formally introduced/analyzed, also in Stock and Watson (2003). However, we extend their work to an open economy 
context, and arrive finally at a prediction model consisting of three simple equations for real economic activity, inflation and real exchange rate. In the empirical analysis we are especially interested in our model's ability to extract the underlying time-varying longrun trends in the forecasts of the aggregate macro data based on simple, but noisy contemporaneous observations from the stock markets.

The rest of the paper proceeds as follows. In section 2 we derive our forecasting model. In section 3 we describe the data used in the empirical analysis and in section 4 we report the results from our empirical analysis based on some standard time series analytical tools. Finally, section 5 gives conclusions and discussion.

\section{Forecasting model based on simple financial market information}

The main idea of our model is to be able to extract prevailing macroeconomic expectations purely from financial market data, where some simple long-run equilibrium conditions have a strong role to play. The starting point in the analysis is the traditional Gordon (1962) growth model that gives the fundamental stock market pricing equation as

$$
P_{t}^{S}=\frac{D_{t}}{i_{t}-g_{t}^{e}-\pi_{t}^{e}}
$$

where the current (time $t$ ) value of equity (stock price) is denoted by $P_{t}^{S}$, and $i_{t}$ is the nominal interest rate at time $t, D_{t}$ is the dividend realized at time $t, g_{t}^{e}$ is the expected growth rate of the economy at time $t$, reflecting the growth possibilities of future real yields on stock investments, and $\pi_{t}^{e}$ is the expected inflation rate at time $t$. Put it simply, equation (1a) states that in equilibrium the current stock price should be a discounted value of the expected future dividend conditional on the available information at time $t$. When compared to the more conventional text-book presentations of this fundamental pricing equation, we actually decompose the required rate of return $k_{t}$ in two timevarying parts, namely the expected growth in dividends mimicked by the real growth rate of aggregate economy, $g_{t}^{e}$, and the real required rate of return from alternative investment targets, given by the risk-free real ex ante rate of interest, $i_{t}-\pi_{t}^{e}{ }^{3}$

\footnotetext{
${ }^{3}$ See Appendix A for a more thorough discussion and derivation of equation (1a).
} 
Note that because (1a) actually involves expectations on more than one variable, it basically gives a dynamic relationship between the current stock price and the explicit, $D_{t}$, and implicit, (i.e. the risks in $g_{t}^{e}$ and $\pi_{t}^{e}$ ), fundamentals which affect it right from the beginning. At this point we do not want to formalize the model in terms of any certain expectations horizons (like daily, monthly or lower frequencies), but wish to keep the representation as general as possible. Equation (1a) can equally well be written in terms of the dividend yield, $d_{t}=D_{t} / P_{t}^{S}$, that is,

$$
d_{t}=i_{t}-g_{t}^{e}-\pi_{t}^{e} \text {. }
$$

In the spirit of Stock and Watson (2003), we next introduce the first, very familiar macroeconomic equilibrium conditions for the nominal and real interest rate, i.e., the Fisher (1930) equation

$$
i_{t}=r_{t}^{e}+\pi_{t}^{e}
$$

and the Euler equation ${ }^{4}$

$$
r_{t}^{e}=\rho+\lambda g_{t}^{e},
$$

as behavioral long-run equilibrium conditions, and not just accounting identities, to the model. In addition to previously defined variables, $r_{t}^{e}$ is here the real (ex ante) interest rate, $\rho$ is the rate of time preference, and $\lambda$ is the inverse of the inter-temporal elasticity of substitution.

Moving towards an open economy extension of this single-country representation involves the use of some additional basic long-run equilibrium conditions. Using a simple two-country setting, we first rewrite the Fisher equation given in (2) for each country in the form

$$
\begin{aligned}
& i_{t}=r_{t}^{e}+E_{t} \Delta P_{t+1} \\
& i_{t}^{*}=r_{t}^{e^{*}}+E_{t} \Delta P_{t+1}^{*},
\end{aligned}
$$

where we use the expectations $(E)$ one period ahead only for notational convenience. Star $\left.{ }^{*}\right)$ now indicates the foreign country variables. Naturally, in terms of investor behavior, the expectations horizon is subjective, and basically directly related to the length of the holding period of investor's asset portfolio or individual assets, but in return calculations

\footnotetext{
${ }^{4}$ Our specification of Euler equation follows Romer's (2006, p. 54 - 56) presentation for household behavior, assuming that the household consumption growth is most strongly connected to the expectations on future aggregate economic activity (see also the introduction in Cochrane (2006)).
} 
based on continuous compounding (that is, continuous trading), expected values for the very next period are the interesting ones for the investor in every period. Hence, we do not fix the investment horizon either. Equation (4) gives the nominal interest rate in each country as the sum of ex ante real interest rate and expected inflation, that is, for example for the home country $\pi_{t}^{e}=E_{t} P_{t+1}-P_{t}=E_{t} \Delta P_{t+1}$ and here $P_{t+1}$ and $P_{t}$ refer now to the $\log$ values of the Consumer Price Index (CPI).

The purchasing power parity (PPP) introduces a long-run goods market condition in the form of differences in the country-wise price levels to the model, yielding for the goods markets between the two countries an equilibrium condition

$$
q_{t}=P_{t}^{*}+S_{t}-P_{t}, \text { that is, } S_{t}=P_{t}-P_{t}^{*}+q_{t},
$$

where in addition to previously defined variables $q_{t}$ is the log of actual real exchange rate at time t, and $S_{t}$ is the log of nominal exchange rate at time t, measured in domestic currency value per unit of foreign currency (the U.S. dollar in our analysis).

After introducing both the financial market equilibrium conditions (1 - 3) and the goods market condition (5) to the model, we need a connection between these two. This comes from adding an uncovered interest parity (UIP) condition to the model, indicating that in an overall long-run equilibrium the current difference between the nominal interest rates in the two countries should equal the expected change in the exchange rate, i.e.,

$$
i_{t}-i_{t}^{*}=E_{t} \Delta S_{t+1} \text {. }
$$

Hence, the final derivation of a testable equation for our 'open economy extension' of the Gordon model starts from formulating the PPP relation in (5) for expected values, which gives

$$
E_{t} S_{t+1}=E_{t} P_{t+1}-E_{t} P_{t+1}^{*}+E_{t} q_{t+1}
$$

Finally, because the main point in our paper is the macroeconomic forecasting ability of the relevant financial market variables, for our forecasting purposes in addition to trying to forecast the future real growth of the economy, we want to view the analysis in terms of expected changes in the price variables (goods prices and the exchange rate), too. These two are the essential ingredients of (4) and (6), so when using the relative version of PPP, we want to give equation (7) actually in the form

$$
E_{t} \Delta S_{t+1}=E_{t} \Delta P_{t+1}-E_{t} \Delta P_{t+1}^{*}+E_{t} \Delta q_{t+1} .
$$

Assuming an overall equilibrium in all the markets analyzed here reflects now replacing the nominal interest rate difference from UIP to the left hand side of (8), which gives us 


$$
i_{t}-i_{t}^{*}=E_{t} \Delta P_{t+1}-E_{t} \Delta P_{t+1}^{*}+E_{t} \Delta q_{t+1} .
$$

On the other hand, from the Fisher equations for both countries we get

$$
E_{t} \Delta P_{t+1}=i_{t}-r_{t}^{e} \quad \text { and } \quad E_{t} \Delta P_{t+1}^{*}=i_{t}^{*}-r_{t}^{e^{*}} .
$$

Placing the Fisher equations now in (9) gives us the equation

$$
i_{t}-i_{t}^{*}=i_{t}-r_{t}^{e}-\left(i_{t}^{*}-r_{t}^{e^{*}}\right)+E_{t} \Delta q_{t+1},
$$

that is,

$$
E_{t} \Delta q_{t+1}=r_{t}^{e}-r_{t}^{e^{*}}
$$

which can be written using the levels of real exchange rate as

$$
q_{t}=E_{t} q_{t+1}-\left(r_{t}^{e}-r_{t}^{e^{*}}\right) .
$$

Hence, the testable equations for our analysis will for the part of the exchange rate variable be based on equation (10), stating that in the long-run equilibrium based on the PPP and UIP conditions the expected real exchange rate can be expressed as the sum of current real exchange rate and the real interest rate difference. In other words, the current real exchange rate is expected real exchange rate minus the difference between the domestic and foreign (ex ante) real interest rates. Most of the literature on PPP (already since Dornbusch (1976)), has stated that the real interest rate difference and the current real exchange rate move in opposite directions, indicating a negative correlation between them. In many later empirical tests in this framework it has been assumed that expectations about the future real exchange rate are constant, but for instance, in Meese and Rogoff (1988) it was pointed out that this assumption is invalid, and market fundamentals would seem to have strong effects on the long run expectations of the real exchange rate, and they should actually be modeled as time-varying expectations. We aim towards this interpretation in our analysis, too.

However, assume for now that the PPP as a long-run hypothesis holds, and hence, the expectations on real exchange rate could be denoted to be constant $(\alpha)$. If we collect all the relevant equations for the equilibrium values of asset prices in our model together, we have for both countries a stock market fundamentals equation (i), that is based on collecting the equilibrium conditions stated in equations (1b) and (3) together and rearranging, and based on equations (2) and (3) a 'Taylor-rule type' interest rate equation (ii), and finally, equation (iii) for the real exchange rate in the two-country context, that is based on equation (10), and assuming there that the PPP holds as a long-run equilibrium condition. Hence, the total system of equations is comprised of 


$$
d_{t}=\rho-(1-\lambda) g_{t}^{e}
$$

$$
i_{t}=\rho+\lambda g_{t}^{e}+\pi_{t}^{e} ; \text { and }
$$

(iii) $q_{t}=\alpha-\left(r_{t}^{e}-r_{t}^{e^{*}}\right)$.

We can see that the country-specific Euler equation is the central building block for the first two equations, and using Euler equations for both countries (namely, that $r_{t}^{e}=\rho+\lambda g_{t}^{e}$ and $\left.r_{t}^{e^{*}}=\rho+\lambda g_{t}^{e^{*}}\right)$, equation (iii) in the above system comes into form ${ }^{5}$

$$
q_{t}=\alpha-\lambda\left(g_{t}^{e}-g_{t}^{e^{*}}\right),
$$

and solving them for the main interesting variables, i.e. the variables concerning expected values first from equations (i) and (ii) yields

$$
\begin{aligned}
& g_{t}^{e}=\frac{\rho}{1-\lambda}-\frac{d_{t}}{1-\lambda} \\
& \pi_{t}^{e}=i_{t}-\frac{\rho}{1-\lambda}+\frac{\lambda d_{t}}{1-\lambda} .
\end{aligned}
$$

Finally, by using the obtained country-wise real growth equilibrium equations, $g_{t}^{e}=\frac{\rho}{1-\lambda}-\frac{d_{t}}{1-\lambda}$ and $g_{t}^{e^{*}}=\frac{\rho}{1-\lambda}-\frac{d_{t}^{*}}{1-\lambda}$, and hence, noting that the dividend yields in the different stock markets are allowed to deviate from each other, from equation (11) we get the third final equation for our system of equations linking the pure financial market information to the development of macro economy. This is an equilibrium condition for the currency market in terms of differences in the dividend yields between foreign and domestic markets, that is

$$
q_{t}=\alpha-\lambda\left(\frac{d_{t}^{*}-d_{t}}{1-\lambda}\right) .
$$

Now we can see that out final total forecasting system (i.e., for expected macro values) of equations is comprised of

\footnotetext{
${ }^{5}$ Here we make use of an assumption on average investors' behavior that in both countries the rate of time preference and the inter-temporal elasticity of substitution are the same and constant, so the differences in real rates of interest are here supposed to come basically from the differences in the growth rates of real economies.
} 


$$
\begin{aligned}
& \text { i) } g_{t}^{e}=\frac{\rho}{1-\lambda}-\frac{d_{t}}{1-\lambda} \\
& \text { ii) } \pi_{t}^{e}=i_{t}-\frac{\rho}{1-\lambda}+\frac{\lambda d_{t}}{1-\lambda} \\
& \text { iii) } \quad q_{t}=\alpha-\lambda\left(\frac{d_{t}^{*}-d_{t}}{1-\lambda}\right),
\end{aligned}
$$

and if we relax the PPP as a long-run hypothesis (i.e. the first term in the equation for the real exchange rate is not a constant), we would have the case where the expectations on real exchange rate are time-varying, and the third equation in the system actually comes into form

$$
q_{t}^{e}=q_{t}+\lambda\left(\frac{d_{t}^{*}-d_{t}}{1-\lambda}\right) .
$$

We propose that this simple system of three equations is able to give the expectations on certain macroeconomic variables, first for the expected real growth and expected inflation and finally, also for the expected real exchange rate, if we are ready to relax the PPP hypothesis.

Especially the third equation in the system requires some discussion on the interpretation. First, let us remind that the dividend yields $d_{t}$ and $d_{t}^{*}$ consist of both the current dividend streams, $D_{t}$ and $D_{t}^{*}$, and current values of the stock prices $P_{t}^{S}$ and $P_{t}^{S^{*}}$ at domestic and foreign markets, respectively. If we assume that the dividend streams in both countries are fairly smooth, i.e., almost constant (but not similar), at least when compared to the stock prices, the interesting part about the discussion actually involves the differences in the stock prices, and hence, expected returns in these two markets. For an intuitive example, in case of assuming that the PPP holds, the analysis can be executed purely in terms of differences in the current stock prices between the two markets. Suppose that for instance the foreign stock market price index at time $t$ has the value of $P_{t}^{S^{*}}=5$, whereas the domestic index is $P_{t}^{S}=6$, and for simplicity, assume that the aggregate market dividend paid in both countries is 0.2 per share, measured in common currency. Hence, the difference in the dividend yields is now greater than zero (because 
$(0.2 / 5)>(0.2 / 6))$ implying a depreciating effect on the current real exchange rate according to the third equation in our system of equations (12).

But for the modification where the PPP hypothesis is relaxed, i.e., when equation (13) is the appropriate equilibrium condition for the expected real exchange rate, we might be tempted to actually think also the stock market variables in terms of current stock prices versus expected stock returns. This indicates analysis in terms of proportional changes in dividend yields in the two countries. If for example $P_{t}^{S^{*}}$ would now be expected to decrease from, say 5 to 4 (that is, the foreign market would crash $20 \%$ ) and correspondingly, the domestic market price is expected to decrease from 6 to 5 (that is, the domestic crash is only $17 \%$ ), this would entail that, ceteris paribus, the proportional change is higher in $P_{t}^{S^{*}}$ than in $P_{t}^{S}$ in terms of expected returns. This gives us a novel hypothesis proposing that as the current $P_{t}^{S^{*}}$ goes down, the expected foreign stock market return (for given, but possibly different dividend streams in both countries) rises, and if the change in the foreign stock prices is proportionally higher than the change in domestic stock prices, that is

$$
R_{t}^{e^{*}}>R_{t}^{e},
$$

where $R_{t}^{e^{*}}$ and $R_{t}^{e}$ are the foreign and domestic expected total stock market returns (comprising of both the capital and dividend yields), we have a case, where the expected real exchange rate $q_{t}^{e}$ appreciates. So basically, when remembering that the higher the current stock price is in either of the markets the lower is the expected return on that market, we obtain here a null hypothesis that because the proportionally high current foreign stock price implies a low foreign dividend yield when compared to the domestic dividend yield, the real exchange rate is expected to appreciate, when $\left(d_{t}^{*}-d_{t}\right)>0$.

\section{Data and descriptive statistics}

Our empirical data consist of monthly observations from the U.K., Japan, Euro-zone and the U.S. The sample period varies for each country depending on the availability of the data. For the U.K. and Japan the sample period is 1978:9 - 2007:1 and for Euro-zone 1979:1 - 2007:1, but divided in two sub-samples so that from the period of 1979:1 1990:12 we use only the German data, and from the latter period the available aggregate 
Euro-zone data. In our analysis the U.S. represent the foreign country, i.e. the world market, against which all the relevant variables, e.g., the exchange rates and dividend yield spreads are calculated. Most of the other data are obtained from the IMF's International Financial Statistics (IFS) and OECD Main Economic Indicators databases, but the dividend yield data are from Datastream ${ }^{6}$. When measured in levels, we convert all data but interest rates and dividend yields to log values, so growth of a certain variable is measured by log difference. We use seasonally adjusted industrial production indexes to describe real economic activity. Nominal interest rates are the 3-month Treasury bill rates.

In addition to the German/Euro-zone sub-sampling we have also divided the data from the U.K. and Japan in different sub-samples for the purposes of controlling some obvious structural changes in these economies during the analyzed period. For the U.K. we have two sub-samples of approximately same size, i.e., first the period 1978:9 - 1992:8, and second, a sub-sample starting from 1992:9, when the U.K. stepped out from the European Exchange Rate Mechanism (ERM). Among other things, this decision amounted to a period of high speculation in the foreign exchange market in general, so the U.K. stepping out from the ERM in September 1992 was an obvious choice for our subsampling point. For Japanese data, the first sub-sample is the period 1978:9 - 1998:12 covering a somewhat 'normal' period of business cycles in the Japanese economy, but in addition, we analyze also the whole sample period (1978:9 - 2007:1) that covers the liquidity trap period approximately after 1999, too.

For preliminary graphical inspection we provide the figures on pair-wise comparisons of the macro and financial market variables in our final system of equations (12). Due to the space limitations we give only the figures for the U.K. data in Figure 1 as an example, but figures for all the other countries are naturally available upon request.

\section{[FIGURE 1 HERE]}

${ }^{6}$ In Datastream the dividend yield is calculated as $d_{t}=100\left(\frac{\sum_{N=1}^{n} D_{t} N_{t}}{\sum_{N=1}^{n} P_{t}^{S} N_{t}}\right)$, where $d_{t}$ is the aggregate dividend yield on day $t$ (and we use the values for the last trading day in each month), $D_{t}$ is the dividend per share on day $t, N_{t}$ is the number of shares in issue on day $t, P_{t}^{S}$ is the unadjusted share price on day $t$, and $n$ is the number of constituents in the index. 
From Figure 1 we see that at first glance the role of 'raw' financial market return data either in terms of the domestic dividend yield and nominal interest rate (and spreads in dividend yields) in forecasting the macro variables is not easy to extract, due to noisy nature of the financial data. However, applying the Hodrick-Prescott (1997) filter to the raw data revealed clearly that already based on purely visual inspection our system of equations might have a role to play in macro forecasting. It would seem that the stock market information has the strongest correlation, at least in terms of the contemporaneous values, with inflation and real exchange rate, plotted in the two middle panels (for inflation) and in the last panel (for real exchange rate). In addition to U.K. data this preliminary conclusion emerged very strongly also from the visual inspection of the data from Germany, Euro-zone and Japan, too.

\section{[TABLE 1 HERE]}

From our descriptive statistics in Table 1 we are able to see that time series on the main interesting variables for our analysis, i.e., the macro variables (growth in the real economic activity, measured by changes in the industrial production, inflation and the real exchange rate) are quite volatile. Dividend yield and dividend yield spreads are very persistent, and actually, we can not reject the null of unit roots in the data generating processes (DGP) of these financial market variables ${ }^{7}$. Furthermore, the coefficients for the first order serial correlation in Table 1 would seem to imply that some of the macro variables are stationary already in levels, whereas the financial market variables (including the short-term nominal interest rate) clearly are not. Hence, for example for the decision on whether to use the variables of our model in levels or in differences in the empirical analysis is not clear-cut at all based on the preliminary data analysis.

Encouraged by these preliminary visual findings and descriptive statistics we next proceed to a more fundamental empirical analysis, and especially to the analysis of the forecasting power of financial market information. We start this from pair-wise Granger

\footnotetext{
${ }^{7}$ Results from the unit root tests based on augmented Dickey-Fuller and KPSS-tests (with constant, but no trend) are available from the authors upon request. The main interesting results were that in addition to real exchange rate series, all the dividend yield series and the dividend yield spreads (i.e., the differences between foreign and domestic dividend yields) were non-stationary for every country and all sample periods. Results for the macro variables were more mixed, but differenced values of all the analyzed variables seemed to behave like stationary variables for every sample and country.
} 
causality tests conducted equation by equation for the variables in the three individual equations in system (12).

\section{Forecasting power of financial market}

Obviously, because the unit root tests implied that some of the variables in our system of equations (12) might be non-stationary, but together they might form some kind of stationary long-run equilibrium relationships (that even might be 'structural' in view of our proposed long-run equilibrium relationships), we had to take into account the possibility of cointegration, and hence, error correction representations of the data, too. Results for this part are not reported here, but the main conclusion from that analysis is that especially for forecasting exercises it was not possible to find any kind of theoretically and empirically relevant (structural and stable) vector error correction representation for the whole system of equations (12). Hence, we proceed towards other types of dynamic representations of our forecasting system and the natural next step in our empirical analysis were the Granger causality tests for the variables in each of the three equations in the system separately.

\section{[TABLE 2 HERE]}

Results from the Granger causality tests strengthen the previous finding that the financial market variables in the individual equations of system (12) are strongly connected to the corresponding macro variables, and furthermore, that the relationship is highly dynamic, because causality seems simultaneous in most cases. This implies strong feedback relations between the financial market and macro data. Put it in other words, at $5 \%$ risk level only in 16 cases out of the total of 70 pair-wise tests the F-statistics indicate that there would not seem to be any causal connections between the analyzed financial and macro variables. More precisely, especially for inflation and real exchange rate data, the feedback relation between the stock market and macro variables seems to have been valid for the analyzed sample periods.

For example in Japan during the liquidity trap period, i.e., since the end of 1990's, the stock market information captured by the spread between domestic and foreign dividend yields seems to have been strongly connected to the behavior of real exchange rate and 
vice versa. Also inflation seems to have been connected to stock market information and nominal interest rate, despite the observed very low levels of both the nominal interest rate and inflation especially at the end of our data period. On the other hand, stock market information would not seem to have any dynamic connections to the real economic growth in Japan or the U.K. (at least after the U.K. stepping out from the ERM), but in the Euro area, and also in the data for the German market, real growth would seem to have had a connection to the stock market performance. In addition, there have clearly emerged strong causal relations from the stock market to inflation in every country and for every sample period.

The Granger causality test results form a strong basis for our next step especially for the part of currency market, because it seems to be the case that the dividend yield spread Granger causes the real exchange rate at least for the Japanese data, but also for the data from the U.K. before the ERM step out, and for the whole U.K. data sample, too. Also in the German data sample the spread would seem to have causal connection to the real exchange rate, but not in the Euro-zone data. However, the strong dynamic connection between the stock market(s) and currency market shows up in the causality from the real exchange rate to the dividend yield spread in every country and every sample period.

Next we move towards the main part of our empirical analysis, which is the out-ofsample forecasting performance of our simple model. We will report all the rest of our results based on the following type of forecasting exercise. We utilize a rolling regression approach with a 5-year moving estimation window in our forecasting analysis ${ }^{8}$. Due to the observed possibility of unit roots in the DGP of some of the variables each individual forecasting equation in system (12) is estimated based on an AR-X-type (i.e., an autoregressive model with additional explanatory variables) dynamic representation with

\footnotetext{
${ }^{8}$ The five-year moving window was utilized in all the out-of-sample forecasting exercises for the individual equations in system (12) and also for the comparison benchmark models based on the fact that many financial market practitioners use the previous 60 months data in their forecasting and performance analyses (see also Griffin (2002), for example). The rolling five-year estimation procedure uses the first 60 observations as the starting sample, and the first 1-, 3-, 6-, 12-, and 24-month out-of-sample forecasts are formed based on these parameter estimates. Then, one observation is added to the end of sample for each variable, whereas the first observation from the beginning is dropped out, keeping the sample size the same 60 as before. This procedure is repeated in a loop until all the observations are utilized, so for example the last longest horizon, i.e., the 24-month out-of-sample forecasts (for January 2007 in the cases of whole sample data) on the macro variables are always based on actual data utilizing the January 2005 observations as the last data point for the estimation of parameter estimates.
} 
2 lags of all the variables in system (12) ${ }^{9}$. In other words, our out-of-sample forecasts are based on regression equations of the following form:

i) $g_{t}=\alpha_{0}^{g}+\alpha_{1}^{g} g_{t-1}+\alpha_{2}^{g} g_{t-2}+\beta_{0}^{g} d_{t}+\beta_{1}^{g} d_{t-1}+\beta_{2}^{g} d_{t-2}+\varepsilon_{t}^{g}$

ii) $\pi_{t}=\alpha_{0}^{\pi}+\alpha_{1}^{\pi} \pi_{t-1}+\alpha_{2}^{\pi} \pi_{t-2}+\beta_{0}^{\pi} d_{t}+\beta_{1}^{\pi} d_{t-1}+\beta_{2}^{\pi} d_{t-2}+\delta_{0}^{\pi} i_{t}+\delta_{1}^{\pi} i_{t-1}+\delta_{2}^{\pi} i_{t-2}+\varepsilon_{t}^{\pi}$

iii) $q_{t}=\alpha_{0}^{q}+\alpha_{1}^{q} q_{t-1}+\alpha_{2}^{q} q_{t-2}+\gamma_{0}^{q}\left(d_{t}^{*}-d_{t}\right)+\gamma_{1}^{q}\left(d_{t-1}^{*}-d_{t-1}\right)+\gamma_{2}^{q}\left(d_{t-2}^{*}-d_{t-2}\right)+\varepsilon_{t}^{q}$,

where in addition to the contemporaneous and one- and two-period lagged values of all the variables in system (12) (notations given in section 2) parameters $\alpha_{i}^{j}, \beta_{i}^{j}, \delta_{i}^{j}$ and $\gamma_{i}^{j}$ are the regression coefficients $(i=0,1,2$, and $j=g, \pi$ or $q)$ and $\varepsilon_{t}^{j}$ denote the error terms in the individual regression equations for each of the macro variables. The parameter estimates and out-of-sample forecasts were obtained from a 5-year rolling regression approach and the forecasting scheme described above for each individual equation separately in our system of equations (14).

Analogously to Stock and Watson (2001) and many other similar types of 'forecasting horse races', when analyzing the system of equations (14) the most natural benchmark models for the comparison of our forecasts are the AR and VAR models. An AR-model for each individual macro variable is obtained basically by restricting the coefficient values on the 'additional' financial market information, i.e., on $d_{t}$ and the lags of it in the first equation of (14), both on $d_{t}, i_{t}$ and their lags in the second, and on $\left(d_{t}^{*}-d_{t}\right)$ and the lags of it in the third equation to zero in each equation individually. Using these zero restrictions for the whole system we obtain the VAR representation for the system of analyzed macro variables. Both AR- and VAR-models (and naturally again with lag length 2) were used as the benchmark models for the calculation of the forecast performance statistics in Tables 3 - 5 .

Before presenting forecast statistics we take a look at the figures on forecasts, and again, due to the space limitations give only some illustrative examples. Now we give the figures from every country (treating always the U.S. as the world market) and for every macro variable, but only for two forecast horizons, i.e. for the 3-month horizon representing the short-term, and the 24-month horizon for the long-term forecasts.

\footnotetext{
${ }^{9}$ Two lags were selected to be optimal based on the Schwarz information criteria obtained from testing for various lag structures also in the VAR-representations of the macro variables' vector $\left(g_{t}, \pi_{t}, q_{t}\right)$ and the finding of unit roots in some of the analyzed macro time series in the whole data set.
} 
Results for all the other forecast horizons are again naturally available upon request. For comparison we plot the figures of forecasts based on our benchmark models, that is, the $A R(2)$ - and VAR(2)-representations and the actual future values of the macro variables in the left-hand panels, whereas the forecasts based on the AR-X-type estimation of the individual equations in system (14) compared to actual future values are in the right-hand panels.

Figures B1 - B4 in Appendix B report the graphs on actual, unfiltered forecast values. However, because the main interest in our forecasting exercise is in attempting to extract the potential of our model in forecasting the underlying, time-varying trends in the future values of the macro-economy, in Figures 2 - 5 we give the corresponding graphs for the Hodrick-Prescott filtered forecasts and future values of the macro variables. When viewing the figures in Appendix B it is obvious that due to the observed strong noise also in the actual forecast values based on our model containing financial data (see Figures B1 - B4) the filtered time series of forecasts reported here in Figures $2-5$ enable a more fundamental comparison of the different forecasting models in terms of their ability to extract the underlying long-run trends in the future values of macro data.

[FIGURE 2 HERE]

[FIGURE 3 HERE]

[FIGURE 4 HERE]

[FIGURE 5 HERE]

A common and strikingly strong overall message from all the Figures $2-5$ is that the financial market information based on system (12) is highly relevant for forecasting real growth and inflation especially for the shorter-term periods. Compared to the German and Euro-zone data, for the more volatile U.K. and Japanese data on industrial production and inflation the additional information introduced in the form of these financial market variables seems to be very important in forecasting the time-varying trends in the macro economy. Also in the longest, i.e., 2-year forecast horizon the financial market 
information clearly helps in forecasting especially the future inflation ${ }^{10}$. When compared to the good forecasting power for real growth and inflation during the era of German data, the time-varying trends in the future values of both the Euro-zone industrial production and inflation are perhaps not so well revealed in the short- and long-term horizons. In Japan the added financial information clearly improves the forecasting power of simple AR- and VAR-models especially for the sample prior to the time period of liquidity trap, but the financial information seems to have a strong role to play in forecasting time-varying trends of future industrial production also in the whole sample data for Japan both at short and long horizons.

For Japanese data also the dividend yield spread against the U.S. market would seem to be a highly relevant information variable in forecasting the time-varying trends in the future values of real exchange rate. Based on visual inspection the equation for forecasting future real exchange rate would not seem to be clearly better in the case of added financial market information in the form of dividend yield spreads for the analyzed European countries.

Our final conclusions on forecast accuracy are based on out-of-sample forecast error statistics given in Tables $3-5$. We report the relative mean squared error (RMSE) values from our model compared to both the benchmark models together with the Diebold and Mariano (1995) test statistics for each country and all the analyzed out-ofsample forecast horizons of $1,3,6,12$, and 24 months. Again, to be able to analyze the models' real ability to extract the underlying time-varying trends we discuss and report here only the results for the filtered time series, and the results for the unfiltered data are given in Tables B1 - B3 in Appendix B.

\section{[TABLE 3 HERE]}

The forecast comparison statistics enforce our preliminary conclusions from visual analysis. The out-of-sample forecasts computed for real growth and inflation detect well

\footnotetext{
${ }^{10}$ In view of the basic idea in the Taylor-rule for the role of short-term nominal interest rate this is not surprising, but based on the statistical significance of the time-varying regression coefficients on the contemporaneous and lagged values of domestic dividend yield the stock market information was also relevant in the inflation equations in many cases. Naturally, the statistical significance of an individual regressor increases the more parsimonious is the model, so statistically the most significant parameter estimates were obtained for the AR-representations, but in our analysis we want to stress more the possible role of additional, financial market information in out-of-sample forecasting terms, so the statistical significance of each individual regressor was not so high on the agenda in this paper right from the beginning.
} 
the time-varying underlying trends in both the data for the U.K. (in Table 3) and Japan (in Table 5), and the common factor in this finding seems to be the ability of our system to detect especially the changes in time-varying underlying trends of macro economy. Compared to the Germany and the Euro-zone, both the U.K. and Japan experienced perhaps even stronger turbulence in the financial markets and macro economy during the analyzed time periods ${ }^{11}$, and for these turbulent times the role of financial market information seems to have been important when forecasting future macro economy.

Based on the results reported in Table 3, prior to the step out from the ERM the AR$\mathrm{X}$-model containing the stock market information forecasts the time-varying trends in real growth extremely well for all forecast horizons compared to both the AR and VAR benchmarks, and for the short-term (1 to 6-month) horizons it is better than at least the AR benchmark also in the most recent data. On the other hand, especially for the data after the U.K. abandoned the ERM the financial market data on nominal interest rate and dividend yield have a strong role to play in forecasting inflation rate at all horizons, even though the shorter horizon forecasts from the AR-X model were more accurate also in the data prior to the ERM step out. Furthermore, for this earlier sample period the dividend yield spread seems to have had a strong role in forecasting the future values of real exchange rate in the U.K. for the money market horizons, but this stock market information would not seem to be so relevant in the most recent data for the U.K.

\section{[TABLE 4 HERE]}

The 'worst' results in terms of the forecast accuracy are obtained for the German and Euro-zone data. From Table 4 we see that our AR-X-type forecasting model is able to 'beat' the benchmark models only for forecasting inflation in the German data. However, when noting that this period of data in the German era was characterized by very low and stable inflation rate, but somewhat high and volatile short-term nominal interest rate ${ }^{12}$, one might be tempted to draw a conclusion that in the inflation forecast equation the role of dividend yield is actually dominated by the role of nominal interest rate in terms of aggressive (and effective) monetary policy directed towards controlling expectations of

\footnotetext{
${ }^{11}$ See also the descriptive statistics of the data in Table 1.

${ }^{12}$ In our data the sample mean of German inflation rate is $0.67 \%$ per annum, and standard deviation is 0.79 , whereas the sample mean of the German 3-month nominal interest rate is 6.48 per annum, and standard deviation is 2.33 .
} 
future inflation. Especially for the Euro-zone data our forecasting system containing financial market information would seem to be somewhat irrelevant when compared to the benchmark AR- and VAR-representations. However, these findings are perhaps not surprising already based on viewing the figures on actual and Hodrick-Prescott filtered values of the macro variables both for the German and Euro-zone eras (see Figures 3 and 4 for the H-P filtered values and Figures B2 and B3 in Appendix B for the unfiltered values). As we see, the macro time series are by far the smoothest for these two eras so the number of possible change points in the underlying time-varying trends is also the smallest in these cases. Hence, already based on visual a priori reasoning the highly noisy financial market information might not have any role in forecasting these smoothly behaving macro time series. This is also the main result obtained from the empirical outof-sample analysis for German and Euro-zone data.

\section{[TABLE 5 HERE]}

For the Japanese data the results speak even more uniformly for the inclusion of financial market data to macro forecasting systems than for the U.K. data. Especially prior to the liquidity trap period the AR-X-model containing the stock market information forecasts the time-varying trends both in real growth and inflation very well for all forecast horizons compared to both the AR and VAR benchmarks. For the part of real exchange rate we obtain the strongest results of all the analyzed countries in Japanese data. For all except the 3-month horizon the dividend yield spread against the U.S market seems to be able to forecast the time-varying trends in future values of real exchange rate, and more specifically, according to the RMSE and D-M statistics the longest term, i.e. 2 years ahead, forecasts seem even to be the most accurate ones.

To put it all together, the main novel finding in our paper seems to be the fact that the stock market dividend yield is a relevant information variable for forecasting the future values of macro economy, at least for real economic growth and inflation, especially during turbulent time periods. For the dividend yield's role as an information variable this is something new compared to the previous findings that speak for the ability of the dividend yield (or the dividend-price ratio) to mimic the expected (or unexpected) stock 
returns $^{13}$, but not actually the future values of macro economy. The financial markets' ability to forecast the time-varying underlying trends even in the longer horizon (like 2 years ahead) macro values is obvious using the derived system of equations based on some simple long-run equilibrium conditions both for the macro economy and financial markets, especially for periods of frequent changes in the time-varying trends of macro economy.

\section{Conclusions}

In this paper we have derived a system of forecasting equations rooted in fundamental long-run equilibrium relationships both for the macro economy and financial markets. The final form for our system of equations consists of a forecasting equation for real growth, inflation, and the real exchange rate. The main explanatory variables are the domestic dividend yield for real growth, the nominal interest rate and the domestic dividend yield for inflation, and the dividend yield spread against the world market for the real exchange rate.

The empirical results from the U.K., Germany, Euro-zone and Japan, treating the U.S. as the world market, show that the stock market dividend yield is a relevant information variable for forecasting the future values of macro economy. The forecasting power shows up especially during turbulent time periods both in the macro economy and financial markets. This is a new result compared to many other studies regarding the role of dividend yield as an informative variable. Previous studies have suggested that the dividend-price ratio is more able to approximate the expected (or unexpected) stock returns, but our results are favorable for using the dividend yield as an actual forecasting variable for future macro economy. Furthermore, when using our system of equations the financial markets' ability to forecast the time-varying underlying trends even in the longer horizon (like 2 years ahead) macro values is obvious, especially during periods of frequent changes in the time-varying trends of the future values of macro economy. Hence, according to our results, inclusion of stock market performance data in some form

\footnotetext{
${ }^{13}$ Early contributions on this finding are Campbell (1991) and Campbell and Ammer (1993), and for more recent evidence, see for example Bekaert et al. (2007) and Campbell and Yogo (2006). Also in the so called Economic Tracking Portfolio (ETP) approach (see Lamont (2001) for more details) the role of dividend yield is more of an instrumental variable, i.e., to serve as an instrument to expected stock market returns.
} 
or the other would seem to be highly recommendable when building even small scale macroeconomic forecasting systems.

All our equations, estimation procedures etc. are based on linear specifications, so the somewhat mixed findings especially on the forecasting ability of the dividend yield spread for future values of real exchange rate might call for more advanced empirical and theoretical analyses, which might for example reveal nonlinearities in the actual data and/or in the relationships between the analyzed financial market and macroeconomic variables. However, because the forecast ability for real economic activity and inflation seems somewhat strong already based on simple linear techniques, the various possibilities for applying nonlinear tools will be left to future work. 


\section{References}

Andersen, T.G., Bollerslev, T., F. X. Diebold, and C. Vega, 2007, "Real-Time Price Discovery in Global Stock, Bond and Foreign Exchange Markets", Journal of International Economics, 73/2, 251-277.

Banerjee, A., and M. Marcellino, 2006, "Are There Any Reliable Leading Indicators for US Inflation and GDP Growth?”, International Journal of Forecasting, 22, 137-151.

Bekaert, G., Harvey, C., R., and C. Lundblad, 2007, "Liquidity and Expected Returns: Lessons from Emerging Markets", The Review of Financial Studies, 20, 1783-1831.

Branson, W.H., and D. W. Henderson, 1985, "The Specification and Influence of Asset Markets", in R. Jones and P. Kenen (eds) Handbook of International Economics, North-Holland, Amsterdam, 749-805.

Campbell, J., Y., 1991 “A Variance Decomposition for Stock Returns,” Economic Journal, 101, 157-79.

Campbell, J., Y., and J. Ammer, 1993, "What Moves the Stock and Bond Markets? A Variance Decomposition for Long-Term Asset Returns, Journal of Finance 48, 3-37.

Campbell, J., Y., and M. Yogo, 2006, "Efficient Tests of Stock Return Predictability" Journal of Financial Economics, 81, 27-60.

Cochrane, J., 2006, Financial Markets and the Real Economy, Edward Elgar, Cheltenham.

Cuthbertson, K., and D. Nitzsche, 2005, Quantitative Financial Economics: Stocks, Bonds \& Foreign Exchange, Wiley, Chichester.

Diebold, F., X., and R S. Mariano, 1995, "Comparing Predictive Accuracy", Journal of Business and Economic Statistics, 13:3, 253-263.

Dornbusch, R., 1976, "Expectations and Exchange Rate Dynamics", Journal of Political Economy, 84, 1161-1176.

Ehrmann, M., M. Fratzscher, and R. Rigobon, 2005, "Stocks, Bonds, Money Markets and Exchange Rates: Measuring International Financial Transmission", NBER Working Paper No 11166.

Fisher, I., 1930, The Theory of Interest, Reprint in 1965, A. M. Kelley, New York.

Francis, B., I. Hasan, and D. M. Hunter, 2006, "Dynamic Relations between International Equity and Currency Markets: The Role of Currency Order Flow", The Journal of Business, 79:1, 219-257.

Gordon, M. J., 1962, The Investment, Financing, and Valuation of the Corporation. Irwin, Homewood, Illinois.

Griffin, J. M., 2002, "Are the Fama and French Factors Global or Country-Specific", The Review of Financial Studies, 15, 783 - 803.

Hamao, Y., R. Masulis, and V. Ng, 1990, "Correlations in Price Changes and Volatility Across International Stock Markets, The Review of Financial Studies, 3, 281-307.

Hau, H., and H. Rey, 2004, "Can Portfolio Rebalancing Explain the Dynamics of Equity returns, Equity Flows, and Exchange Rates?", American Economic Review, 94:2, 126-133.

Hau, H., and H. Rey, 2006, "Exchange Rates, Equity Prices, and Capital Flows", The Review of Financial Studies, 19/1, 273-317.

Hodrick, R., J., and E. C. Prescott, 1997, "Post-war U.S. Business Cycles: An Empirical Investigation", Journal of Money, Credit and Banking, 29, 1-16.

Kouri, P. J. K., 1982, "Balance of Payment and the Foreign Exchange Market: A Dynamic Partial Equilibrium Model", in J. Bhandari and B. Putnam (eds) Economic Interdependence and Flexible Exchange Rates, MIT Press, Cambridge, 116-156.

Lamont, O., 2001, "Economic Tracking Portfolios," Journal of Econometrics, 105, 161-184.

Marcellino, M., J. H. Stock, and M. W. Watson, 2003, "Macroeconomic Forecasting in the Euro Area: Country-Specific versus Area-Wide Information", European Economic Review, 47, $1-18$.

Meese, R., and K. Rogoff, 1988, "Was it Real? The Exchange Rate-Interest Differential Relation over the Modern Floating-Rate Period", The Journal of Finance, Vol XLIII, 933-948.

Mitchell, W.,C., and A.F. Burns, 1938, Statistical Indicators of Cyclical Revivals, NBER Bulletin 
69, NY., Reprinted in G.H. Moore (ed) Business Cycle Indicators, Princeton University Press, Princeton.

Pavlova, A., and R. Rigobon, 2007, "Asset Prices and Exchange Rates", The Review of Financial Studies, 20/4, 1139-1181.

Phylaktis, K., and F. Ravazzolo, 2005, "Stock Prices and Exchange Rate Dynamics", Journal of International Money and Finance, 24, 1031-1053.

Romer, D., 2006, Advanced Macroeconomics, $2^{\text {nd }}$ ed., McGraw-Hill, Irwin.

Stock, J.H., and M.W. Watson, 2001, "Vector Autoregressions", Journal of Economic Perspectives, 15:4, 101-115.

Stock, J.H., and M.W. Watson, 2003, "Forecasting Output and Inflation: The Role of Asset Prices", Journal of Economic Literature, Vol XLI, 788-829.

Susmel, R., and R. Engle, 1994, "Hourly Volatility Spillovers Between International Equity Markets", Journal of International Money and Finance, 13, 3-25 


\section{Appendix A}

The usual starting point when applying the Gordon (1962) growth model in the stock market analysis is some version of equation

$$
P_{t}^{S}=E_{t}\left(P_{t+1}^{S}+D_{t+1}\right) /(1+k),
$$

where $k$ is the agents' discount rate for future utility (assumed constant in the static version), $P_{t}^{S}$ is the current price of equity share, and $D_{t+1}$ is the dividend accruing to the ownership of the equity share during the holding period. Hence, in equilibrium the current stock price should be the discounted value of the expected future dividend and future price conditional on the available information at time $t$. We may derive an asset pricing formula from equation (A1) by recursive substitution, yielding for the first round

$$
P_{t}^{S}=E_{t}\left[D_{t+1}+E_{t+1}\left(D_{t+2}+P_{t+2}^{S}\right) /(1+k)\right] /(1+k) .
$$

Updating equation (A1) again $i$ times, substituting for each $P_{t+i}^{S}$ from this recursive operation into equation (A2) and using the law of iterated expectations $E_{t}\left(E_{t+1}\left(D_{t+2}\right)\right)=E_{t}\left(D_{t+2}\right)$ with an infinite number of substitutions, we are able to find that the current price on the asset is the expected value of all future dividends, i.e.,

$$
P_{t}^{f}=\sum_{i=1}^{\infty}[1 /(1+k)]^{i} E_{t}\left(D_{t+i}\right) .
$$

In equation (A3) superscript $f$ now refers to the market fundamentals price. Equation (A3) is often referred to as the so-called rational valuation formula (RVF) for the stock price ${ }^{14}$. In deriving this formula we have imposed the terminal or transversality condition $\lim _{i \rightarrow \infty}\left[E\left(P_{t+i}^{S}\right) /(1+k)^{i}\right]=0$, implying that the pricing equation (A3) has a finite number of possible solutions. Due to the obvious role of the expectations on future dividends and the discount factor in the rational valuation formula a natural question that arises from this equation concerns the role of economic factors, i.e., state variables that might have effects on either or both of these two main components of the return generating process of common stocks in general. This is the part where we address the role of expectations about future economic growth and inflation, i.e. macroeconomic activity. More specifically, we want to allow both for time-varying discount factor $\left(k_{t}\right)$ and time-varying dividends in our analysis, where time-variation is mainly based on expectations regarding real economic variables.

The simplest model for time-variation in dividends is the AR(1) model, i.e.

$$
D_{t+1}=(1+g) D_{t}+w_{t+1},
$$

\footnotetext{
${ }^{14}$ See also Cuthbertson and Nitzsche (2005), where details on applying RVF in other than stock markets, too, are given.
} 
where $g$ is the (constant) growth rate of dividends, and $w_{t+1}$ is the white noise term. In this case, expected dividend growth is

$$
g=\frac{E_{t} D_{t+1}-D_{t}}{D_{t}}
$$

and the optimal forecasts of future dividends may be found by leading (A4) and by repeated substitution as

$$
E_{t} D_{t+i}=(1+g)^{i} D_{t}
$$

Substituting now the forecast of future dividends from (A5) in the RVF gives

$$
P_{t}=\sum_{i=1}^{\infty} \frac{(1+g)^{i} D_{t}}{(1+k)^{i}}
$$

and after some simple algebra we obtain the Gordon growth model now in the form

$$
P_{t}=\frac{(1+g)}{(k-g)} D_{t} \quad \text { with }(k-g)>0 .
$$

If for example $g=0.02$, and $k=0.06$, the price-dividend ratio (i.e., inverse of the dividend yield utilized in the main text) is 25.5 , and if agents suddenly revise their expectations of $g$ or $k$, prices will move substantially. Assuming that for example $g$ falls to 0.01 , ceteris paribus, the new pricedividend ratio would be 14.4 , implying a dramatic 'crash' in equity price of $43.5 \%$.

For our application also the notion that rational investors might require a different expected return in each future period in order to hold a stock portfolio is important. Therefore, the expected one-period total return on stocks $E_{t} R_{t+1}=\frac{E_{t} P_{t+1}^{S}-P_{t}^{S}+E_{t} D_{t+1}}{P_{t}^{S}}$ should equal the required rate of return $k_{t+1}$ for her, implying that also the required rate of return is time-varying. Repeating again the previous steps, involving also forward substitutions now gives

$$
\begin{gathered}
P_{t}^{S}=E_{t}\left[\left(1+k_{t+1}\right)^{-1} D_{t+1}+\left(1+k_{t+1}\right)^{-1}\left(1+k_{t+2}\right)^{-1} D_{t+2}+\ldots\right. \\
\left.+\ldots\left(1+k_{t+N-1}\right)^{-1}\left(1+k_{t+N}\right)^{-1}\left(D_{t+N}+P_{t+N}^{S}\right)\right]
\end{gathered}
$$

which can be written in a more compact form as

$$
P_{t}^{S}=E_{t}\left[\sum_{j=1}^{\infty}\left[\prod_{i=1}^{j}\left(1+k_{t+i}\right)^{-1}\right] D_{t+j}\right] \equiv E_{t} \sum_{j=1}^{\infty}\left(1+k_{t, t+j}\right)^{-1} D_{t+j} .
$$

Put it in other words, the main message is now that the current stock price depends both on expectations of future discount rates and dividends. However, the severe problem in (A6) is that it is more or less 'non-operational' as a pricing equation, because it contains unobservable expectation terms, and like Cuthbertson and Nitzsche (2005) argue, in applied work we usually would need some ancillary tractable hypotheses about investors' forecasts of dividends and the discount rate to move towards empirical analysis. 
Our innovation for this part is that, when our aim is to provide evidence on the forecasting power of financial market information for future macro economy we should not even try to develop for example AR-type forecasting models for dividends or the equilibrium rate of return. We argue that in this case it is enough to note that when financial market participants make there investment decisions over time, they have some kind of rational expectation forecasts, i.e., expectations about the development of macro economy in the future in mind, and these expectations affect both the expected dividends and expected returns, so it must be the case that the current stock market price and/or return information mirrors these expectations in some way. Hence, in this case it is enough to formalize the basic Gordon growth model in the form given in the main text, i.e.,

$$
P_{t}^{S}=\frac{D_{t}}{i_{t}-g_{t}^{e}-\pi_{t}^{e}}
$$

that basically factorizes the discount factor $\left(k_{t}\right)$ described above in two components, i.e. the expected real growth of the economy $\left(g_{t}^{e}\right)$, mimicking the potential growth rate of future dividends, and the (ex ante) real rate of interest $\left(i_{t}-\pi_{t}^{e}\right)$, at least partly capturing the role of time varying expected returns. In this paper we aim to utilize this long-run equilibrium version of the Gordon model as the starting formulation for our open economy extension. 


\section{TABLES AND FIGURES}

\section{Table 1}

\section{Descriptive statistics}

\begin{tabular}{|c|c|c|c|c|c|c|c|c|c|c|c|c|c|c|}
\hline \multirow[t]{2}{*}{ Variable } & \multicolumn{2}{|c|}{$\begin{array}{c}U . K . \\
\text { (sample 1978:9- } \\
\text { 1992:8) }\end{array}$} & \multicolumn{2}{|c|}{$\begin{array}{c}U . K . \\
\text { (sample 1992:9- } \\
\text { 2007:1) }\end{array}$} & \multicolumn{2}{|c|}{$\begin{array}{c}\text { Germany } \\
\text { (sample 1979:1 - } \\
\text { 1990:12) }\end{array}$} & \multicolumn{2}{|c|}{$\begin{array}{c}\text { Eurozone } \\
\text { (sample 1991:1 - } \\
\text { 2007:1) }\end{array}$} & \multicolumn{2}{|c|}{$\begin{array}{c}\text { Japan } \\
\text { (sample 1978:9- } \\
\text { 1998:12) }\end{array}$} & \multicolumn{2}{|c|}{$\begin{array}{c}\text { Japan } \\
\text { (sample 1978:9 - } \\
\text { 2007:1) }\end{array}$} & \multicolumn{2}{|c|}{$\begin{array}{c}U . S . \\
\text { (sample 1978:9- } \\
2007: 1)\end{array}$} \\
\hline & Mean & $\rho_{1}$ & Mean & $\rho_{1}$ & Mean & $\rho_{1}$ & Mean & $\rho_{1}$ & Mean & $\rho_{1}$ & Mean & $\rho_{1}$ & Mean & $\rho_{1}$ \\
\hline$g_{t}$ & $\begin{array}{c}.91 \\
(17.98)\end{array}$ & -.29 & $\begin{array}{c}.80 \\
(9.69)\end{array}$ & -.30 & $\begin{array}{c}4.14 \\
(16.18)\end{array}$ & -.42 & $\begin{array}{c}1.45 \\
(10.02)\end{array}$ & -.35 & $\begin{array}{c}2.62 \\
(16.57)\end{array}$ & -.35 & $\begin{array}{c}1.98 \\
(16.41)\end{array}$ & -.33 & $\begin{array}{c}2.43 \\
(7.53)\end{array}$ & -.24 \\
\hline$\pi_{t}$ & $\begin{array}{c}7.22 \\
(7.83)\end{array}$ & .33 & $\begin{array}{c}2.58 \\
(4.37)\end{array}$ & .05 & $\begin{array}{l}.67 \\
(.79)\end{array}$ & .49 & $\begin{array}{c}2.04 \\
(3.91)\end{array}$ & -.03 & $\begin{array}{l}1.95 \\
(6.40)\end{array}$ & .09 & $\begin{array}{c}1.27 \\
(5.78)\end{array}$ & .12 & $\begin{array}{c}3.93 \\
(4.13)\end{array}$ & .57 \\
\hline$q_{t}$ & $\begin{array}{l}-.42 \\
(.16)\end{array}$ & .98 & $\begin{array}{l}-.42 \\
(.14)\end{array}$ & .98 & $\begin{array}{l}.75 \\
(.20)\end{array}$ & .99 & $\begin{array}{l}-.13 \\
(.12)\end{array}$ & .98 & $\begin{array}{l}5.05 \\
(.32)\end{array}$ & .99 & $\begin{array}{l}4.97 \\
(.31)\end{array}$ & .99 & - & - \\
\hline$d_{t}$ & $\begin{array}{l}4.94 \\
(.76)\end{array}$ & .93 & $\begin{array}{l}3.32 \\
(.55)\end{array}$ & .97 & $\begin{array}{l}2.81 \\
(.79)\end{array}$ & .98 & $\begin{array}{l}2.45 \\
(.52)\end{array}$ & .97 & $\begin{array}{l}1.03 \\
(.47)\end{array}$ & .99 & $\begin{array}{c}.09 \\
.99 \\
(.41)\end{array}$ & .99 & $\begin{array}{c}3.19 \\
(1.45)\end{array}$ & .99 \\
\hline$i_{t}$ & $\begin{array}{l}11.46 \\
(2.16)\end{array}$ & .94 & $\begin{array}{c}5.22 \\
(1.02)\end{array}$ & .98 & $\begin{array}{c}6.48 \\
(2.33)\end{array}$ & .99 & $\begin{array}{c}4.78 \\
(2.33)\end{array}$ & .99 & $\begin{array}{c}4.92 \\
(2.87)\end{array}$ & .98 & $\begin{array}{c}3.57 \\
(3.24)\end{array}$ & .99 & $\begin{array}{c}7.13 \\
(3.71)\end{array}$ & .98 \\
\hline$d_{t}^{*}-d_{t}$ & $\begin{array}{l}-.62 \\
(.70)\end{array}$ & .94 & $\begin{array}{l}-1.53 \\
(.30)\end{array}$ & .93 & $\begin{array}{l}1.66 \\
(.53)\end{array}$ & .89 & $\begin{array}{l}-.54 \\
(.49)\end{array}$ & .97 & $\begin{array}{c}2.62 \\
(1.03)\end{array}$ & .99 & $\begin{array}{c}2.03 \\
(1.27)\end{array}$ & .99 & - & - \\
\hline
\end{tabular}

Variables in the table are as follows: $g_{t}$ is the growth rate of real economy, measured by the log difference of the industrial production index (seasonally adjusted), $\pi_{t}$ is the annualized inflation rate, based on the Consumer Price Index (CPI), $q_{t}=S_{t}+P_{t}^{*}-P_{t}$ is the (log) of real exchange rate, based on adding the (log of) nominal spot exchange rate $S_{t}$ (end-of-period domestic currency price/U.S. dollar) to the difference in the foreign $\left(P^{*}\right)$ and domestic $(P)$ log CPI-price levels (hence, a higher value implies depreciation of the nominal value of domestic currency), $d_{t}$ and $d_{t}^{*}$ are the domestic and foreign (i.e., the U.S. yield in the spread calculation) dividend yields, respectively, and finally, $i_{t}$ is the nominal short-tem (3-month) interest rate. The numbers in parentheses under the mean values are standard deviations, and $\rho_{1}$ denotes the first-order autocorrelation coefficient. All the growth measures are given as annualized percentage values. 
Table 2

Bivariate Granger causality test results

\begin{tabular}{|c|c|c|c|c|c|c|c|}
\hline Null Hypothesis & $\begin{array}{c}U . K . \\
\text { (sample 1978:9 } \\
-2007: 1 \text { ) }\end{array}$ & $\begin{array}{c}U . K . \\
\text { (sample 1978:9 } \\
-1992: 8 \text { ) }\end{array}$ & $\begin{array}{c}U . K . \\
\text { (sample 1992:9 } \\
\text { - 2007:1) }\end{array}$ & $\begin{array}{c}\text { Germany } \\
\text { (sample 1979:1 } \\
\text { - 1990:12) }\end{array}$ & $\begin{array}{c}\text { Eurozone } \\
\text { (sample 1991:1 } \\
-2007: 1 \text { ) }\end{array}$ & $\begin{array}{c}\text { Japan } \\
\text { (sample 1978:9 } \\
-2007: 1 \text { ) }\end{array}$ & $\begin{array}{c}\text { Japan } \\
\text { (sample 1978:9 } \\
-1998: 12 \text { ) }\end{array}$ \\
\hline \multirow{2}{*}{$d_{t}$ fails to cause $g_{t}$} & 1.57 & 1.37 & .92 & 1.72 & 1.09 & .89 & 1.05 \\
\hline & $(.10)$ & $(.18)$ & $(.53)$ & $(.08)$ & $(.37)$ & $(.55)$ & $(.41)$ \\
\hline \multirow{2}{*}{$g_{t}$ fails to cause $d_{t}$} & .64 & 3.12 & .66 & 3.74 & 5.84 & .18 & .14 \\
\hline & $(.81)$ & $(<.001)$ & $(.79)$ & $(<.001)$ & $(<.001)$ & (.99) & (.99) \\
\hline \multirow{2}{*}{$d_{t}$ fails to cause $\pi_{t}$} & 6.83 & 2.26 & 2.50 & 4.44 & 2.22 & 2.18 & 1.90 \\
\hline & $(<.001)$ & $(.01)$ & $(.004)$ & $(<.001)$ & $(.01)$ & $(.01)$ & $(.04)$ \\
\hline \multirow{2}{*}{$\pi_{t}$ fails to cause $d_{t}$} & 49.02 & 19.08 & .20 & 17.96 & 4.11 & 12.71 & 12.50 \\
\hline & $(<.001)$ & $(<.001)$ & (.99) & $(<.001)$ & $(<.001)$ & $(<.001)$ & $(<.001)$ \\
\hline \multirow{2}{*}{$i_{t}$ fails to cause $\pi_{t}$} & 9.15 & 3.28 & 2.23 & 3.55 & 1.16 & 6.70 & 4.44 \\
\hline & $(<.001)$ & $(<.001)$ & $(.01)$ & $(<.001)$ & $(.31)$ & $(<.001)$ & $(<.001)$ \\
\hline \multirow{2}{*}{$\pi_{t}$ fails to cause $i_{t}$} & 66.49 & 23.50 & 3.66 & 34.26 & 21.48 & 71.59 & 30.88 \\
\hline & $(<.001)$ & $(<.001)$ & $(<.001)$ & $(<.001)$ & $(<.001)$ & $(<.001)$ & $(<.001)$ \\
\hline \multirow{2}{*}{$i_{t}$ fails to cause $d_{t}$} & 48.54 & 6.90 & 1.87 & 11.68 & 2.43 & 8.36 & 7.80 \\
\hline & $(<.001)$ & $(<.001)$ & $(.04)$ & $(<.001)$ & $(.01)$ & $(<.001)$ & $(<.001)$ \\
\hline \multirow{2}{*}{$d_{t}$ fails to cause $i_{t}$} & 57.52 & 7.34 & .81 & 9.28 & 2.91 & 6.62 & 7.38 \\
\hline & $(<.001)$ & $(<.001)$ & (.64) & $(<.001)$ & $(.001)$ & $(<.001)$ & $(<.001)$ \\
\hline \multirow{2}{*}{$d_{t}^{*}-d_{t}$ fails to cause $q_{t}$} & 7.94 & 6.15 & 1.54 & 14.65 & 1.10 & 45.33 & 33.31 \\
\hline & $(<.001)$ & $(<.001)$ & $(.12)$ & $(<.001)$ & $(.36)$ & $(<.001)$ & $(<.001)$ \\
\hline \multirow{2}{*}{$q_{t}$ fails to cause $d_{t}^{*}-d_{t}$} & 7.01 & 4.92 & 4.71 & 10.08 & 10.84 & 48.67 & 28.88 \\
\hline & $(<.001)$ & $(<.001)$ & $(<.001)$ & $(<.001)$ & $(<.001)$ & $(<.001)$ & $(<.001)$ \\
\hline
\end{tabular}

The reported Granger causality F-test statistics are computed based on 12 lags. The numbers in parentheses are $p$-values for the null of no causality. See the notations for variables below Table 1. 
Table 3

Out-of-sample forecast error statistics for the U.K.; Hodrick-Prescott filtered forecasts

\begin{tabular}{|c|c|c|c|c|c|c|c|c|c|c|c|c|}
\hline \multirow[b]{2}{*}{$\begin{array}{c}\text { Period } \\
\text { 1985:8 - 2007:1 } \\
\text { Forecast horizon }\end{array}$} & \multicolumn{4}{|c|}{ g; real growth } & \multicolumn{4}{|c|}{$\pi ;$ inflation rate } & \multicolumn{4}{|c|}{$q$ : real exchange rate } \\
\hline & $\begin{array}{c}\text { RMSE of } \\
\text { AR-X } \\
\text { against } \\
\text { AR } \\
(\%)\end{array}$ & $\begin{array}{c}D-M \text { for } \\
A R-X \\
v s . \\
A R\end{array}$ & $\begin{array}{c}\text { RMSE of } \\
\text { AR-X } \\
\text { against } \\
\text { VAR } \\
(\%)\end{array}$ & $\begin{array}{c}D-M \text { for } \\
A R-X \\
v s . \\
V A R\end{array}$ & $\begin{array}{c}\text { RMSE of } \\
\text { AR-X } \\
\text { against } \\
\text { AR } \\
(\%)\end{array}$ & $\begin{array}{c}D-M \text { for } \\
A R-X \\
v s . \\
A R\end{array}$ & $\begin{array}{c}\text { RMSE of } \\
\text { AR-X } \\
\text { against } \\
\text { VAR } \\
(\%)\end{array}$ & $\begin{array}{c}D-M \text { for } \\
A R-X \\
v s . \\
V A R\end{array}$ & $\begin{array}{c}\text { RMSE of } \\
\text { AR-X } \\
\text { against } \\
\text { AR } \\
(\%)\end{array}$ & $\begin{array}{c}\text { D-Mfor } \\
A R-X \\
v s . \\
A R\end{array}$ & $\begin{array}{l}\text { RMSE of } \\
\text { AR-X } \\
\text { against } \\
\text { VAR } \\
(\%)\end{array}$ & $\begin{array}{c}D-M \text { for } \\
A R-X \\
\text { vs. } \\
V A R\end{array}$ \\
\hline $\begin{array}{c}1 \\
3 \\
6 \\
12 \\
24 \\
\end{array}$ & $\begin{array}{c}59.40 \\
51.08 \\
70.99 \\
73.83 \\
100.86 \\
\end{array}$ & $\begin{array}{c}-5.46^{* * * *} \\
-6.45^{* * *} \\
-4.47^{* * *} \\
-4.66^{* * * *} \\
-.10 \\
\end{array}$ & $\begin{array}{l}55.39 \\
69.86 \\
82.16 \\
81.77 \\
91.58\end{array}$ & $\begin{array}{l}-6.69^{* * *} \\
-5.27^{* * *} \\
-3.31^{* * *} \\
-3.29^{* * *} \\
-1.46^{*}\end{array}$ & $\begin{array}{c}49.73 \\
49.50 \\
55.40 \\
95.53 \\
136.70 \\
\end{array}$ & $\begin{array}{c}-5.19^{* * * *} \\
-5.00^{* * *} \\
-4.28^{* * *} \\
-1.24 \\
-2.16^{\mathrm{BBB}} \\
\end{array}$ & $\begin{array}{c}41.55 \\
50.34 \\
55.24 \\
80.89 \\
120.69\end{array}$ & $\begin{array}{l}-5.59^{* * * *} \\
-4.23^{* * *} \\
-3.31^{* * * *} \\
-3.29^{* * *} \\
-1.46^{\mathrm{B}}\end{array}$ & $\begin{array}{c}102.99 \\
132.42 \\
91.14 \\
78.21 \\
207.47\end{array}$ & $\begin{array}{c}.46 \\
-3.75^{\text {BBB }} \\
-1.35^{*} \\
-2.85^{* * *} \\
-4.15^{\text {BBB }}\end{array}$ & $\begin{array}{c}106.15 \\
143.04 \\
93.91 \\
76.79 \\
179.93\end{array}$ & $\begin{array}{c}.87 \\
-4.64^{\mathrm{BBB}} \\
-.88 \\
-2.89^{* * *} \\
-3.33^{\mathrm{BBB}}\end{array}$ \\
\hline $\begin{array}{c}\text { Period } \\
\text { 1985:8 - 1992:8 } \\
\text { Forecast horizon }\end{array}$ & & & & & & & & & & & & \\
\hline $\begin{array}{c}1 \\
3 \\
6 \\
12 \\
24\end{array}$ & $\begin{array}{l}47.74 \\
50.79 \\
65.52 \\
62.55 \\
81.16\end{array}$ & $\begin{array}{l}-6.01^{* * *} \\
-6.03^{* * *} \\
-5.44^{* * *} \\
-8.60^{* * *} \\
-2.26^{* *}\end{array}$ & $\begin{array}{l}35.51 \\
55.91 \\
76.00 \\
81.71 \\
72.57\end{array}$ & $\begin{array}{l}-10.55^{\text {*** }} \\
-7.92^{\text {*** }} \\
-4.95^{\text {*** }} \\
-4.91^{\text {*** }} \\
-8.89^{\text {*** }}\end{array}$ & $\begin{array}{c}71.82 \\
74.35 \\
83.28 \\
122.32 \\
175.02\end{array}$ & $\begin{array}{c}-2.26^{* *} \\
-2.03^{* *} \\
-1.26 \\
-1.16 \\
-3.14^{\mathrm{BBB}}\end{array}$ & $\begin{array}{c}54.99 \\
68.03 \\
74.43 \\
115.56 \\
154.86\end{array}$ & $\begin{array}{c}-3.46^{* * *} \\
-2.14^{* *} \\
-1.55^{*} \\
-.67 \\
-2.48^{\mathrm{BBB}}\end{array}$ & $\begin{array}{c}87.88 \\
90.30 \\
72.01 \\
65.50 \\
171.22\end{array}$ & $\begin{array}{l}-2.90^{* * *} \\
-.58 \\
-2.20^{* *} \\
-2.84^{* * *} \\
-2.25^{\mathrm{BB}}\end{array}$ & $\begin{array}{c}89.23 \\
89.07 \\
69.04 \\
62.30 \\
141.87\end{array}$ & $\begin{array}{l}-2.76^{* * *} \\
-.69 \\
-2.44^{* * *} \\
-3.07^{* * *} \\
-1.48^{\mathrm{B}}\end{array}$ \\
\hline $\begin{array}{c}\text { Period } \\
\text { 1992:9-2007:1 } \\
\text { Forecast horizon }\end{array}$ & & & & & & & & & & & & \\
\hline $\begin{array}{c}1 \\
3 \\
6 \\
12 \\
24\end{array}$ & $\begin{array}{c}74.65 \\
53.15 \\
78.25 \\
87.31 \\
145.07\end{array}$ & $\begin{array}{l}-2.14^{* *} \\
-3.48^{* * *} \\
-1.75^{* *} \\
-1.04 \\
2.59^{\mathrm{BB}}\end{array}$ & $\begin{array}{c}104.31 \\
108.25 \\
90.26 \\
81.87 \\
136.42\end{array}$ & $\begin{array}{c}-.42 \\
-.64 \\
-.91 \\
-1.61^{*} \\
-2.18^{\mathrm{BB}}\end{array}$ & $\begin{array}{l}17.11 \\
13.76 \\
16.44 \\
27.17 \\
67.56\end{array}$ & $\begin{array}{l}-5.37^{* * * *} \\
-5.15^{* * *} \\
-5.06^{* * *} \\
-4.62^{* * *} \\
-2.10^{* *}\end{array}$ & $\begin{array}{l}16.52 \\
17.42 \\
20.11 \\
27.27 \\
59.42\end{array}$ & $\begin{array}{l}-4.83^{* * * *} \\
-4.39^{* * * *} \\
-4.40^{* * * *} \\
-4.39^{* * *} \\
-2.66^{* *}\end{array}$ & $\begin{array}{c}140.00 \\
150.00 \\
105.36 \\
96.44 \\
285.36\end{array}$ & $\begin{array}{c}-6.91^{\mathrm{BBB}} \\
-5.67^{\mathrm{BBB}} \\
-.93 \\
-.65 \\
-6.50^{\mathrm{BBB}}\end{array}$ & $\begin{array}{c}158.33 \\
175.22 \\
115.45 \\
99.39 \\
295.61\end{array}$ & $\begin{array}{c}-9.46^{\mathrm{BBB}} \\
-7.78^{\mathrm{BBB}} \\
-2.64^{\mathrm{BBB}} \\
-.11 \\
-6.64^{\mathrm{BBB}}\end{array}$ \\
\hline
\end{tabular}

We report the relative mean squared error statistics against the H-P-filtered future values (in \%) in the first and third columns for each macro variable; values below 100 indicate that the AR-X model containing financial variables is better than the benchmark model (either an AR(2)-representation for the variable in question, or a VAR(2)-system for the vector of all the three macro variables). D-M refers to the Diebold - Mariano (1995)- test statistics for the comparison of the AR-X model to the benchmark models; ***, ** and * refer to the cases where the AR-X is better than the benchmark at 1, 5 or $10 \%$ significance levels, respectively, whereas BBB, BB, or B to the cases where the corresponding benchmark model is better, respectively. 
Table 4

Out-of-sample forecast error statistics for Germany and the Euro-zone; Hodrick-Prescott filtered forecasts

\begin{tabular}{|c|c|c|c|c|c|c|c|c|c|c|c|c|}
\hline & \multicolumn{4}{|c|}{ g; real growth } & \multicolumn{4}{|c|}{$\pi ;$ inflation rate } & \multicolumn{4}{|c|}{$q$ : real exchange rate } \\
\hline & RMSE of & $D-M$ for & RMSE of & $D-M$ for & RMSE of & $D-M$ for & RMSE of & $D-M$ for & RMSE of & $D-M$ for & RMSE of & $D-M$ for \\
\hline & $A R-X$ & $A R-X$ & $A R-X$ & $A R-X$ & $A R-X$ & $A R-X$ & $A R-X$ & $A R-X$ & $A R-X$ & $A R-X$ & $A R-X$ & $A R-X$ \\
\hline Germany & against & $v s$. & against & $v s$ & against & $v s$ & against & $v s$ & against & $v s$. & against & $v s$. \\
\hline 1985:8 - 1990:12 & $A R$ & $A R$ & $V A R$ & $V A R$ & $A R$ & $A R$ & $V A R$ & $V A R$ & $A R$ & $A R$ & $V A R$ & $V A R$ \\
\hline & $(\%)$ & & $(\%)$ & & $(\%)$ & & $(\%)$ & & $(\%)$ & & $(\%)$ & \\
\hline \multicolumn{13}{|l|}{ Forecast horizon } \\
\hline 1 & 107.46 & -.44 & 46.06 & $-4.32^{* * *}$ & 38.55 & $-4.26^{* * *}$ & 38.00 & $-3.88^{* * *}$ & 97.64 & -.28 & 103.50 & -.34 \\
\hline 3 & 169.52 & $-3.82^{\mathrm{BBB}}$ & 99.60 & -.03 & 17.99 & $-5.70^{* * * *}$ & 17.86 & $-5.03^{* * *}$ & 152.23 & $-3.57^{\mathrm{BBB}}$ & 182.69 & $-3.67^{\mathrm{BBB}}$ \\
\hline 6 & 161.98 & $-2.72^{\mathrm{BBB}}$ & 79.19 & -1.28 & 16.27 & $-5.93^{* * * *}$ & 17.08 & $-6.73^{* * * *}$ & 101.32 & -.13 & 103.99 & -.30 \\
\hline 12 & 228.26 & $-3.62^{\mathrm{BBB}}$ & 93.57 & -.43 & 19.32 & $-5.47^{* * * *}$ & 22.13 & $-9.69^{* * *}$ & 94.55 & -.75 & 96.63 & -.38 \\
\hline 24 & 301.03 & $-2.82^{\text {BBB }}$ & 126.33 & -1.08 & 22.72 & $-5.01^{* * * *}$ & 40.75 & $-14.13^{* * *}$ & 175.22 & $-4.67^{\mathrm{BBB}}$ & 288.65 & $-6.44^{\mathrm{BBB}}$ \\
\hline \multicolumn{13}{|l|}{$\begin{array}{c}\text { Euro-zone } \\
\text { 1998:1 - 2007:11 }\end{array}$} \\
\hline \multicolumn{13}{|l|}{ Forecast horizon } \\
\hline 1 & 114.30 & -.98 & 68.57 & $-2.86^{* * *}$ & 180.95 & $-3.91^{\mathrm{BBB}}$ & 107.61 & -.57 & 282.20 & $-8.81^{\mathrm{BBB}}$ & 141.16 & $-2.50^{\mathrm{BBB}}$ \\
\hline 3 & 119.78 & -1.17 & 76.22 & $-1.78^{* *}$ & 130.76 & $-1.51^{\mathrm{BB}}$ & 76.47 & $-1.77^{\mathrm{BB}}$ & 270.76 & $-7.71^{\mathrm{BBB}}$ & 261.29 & $-5.96^{\mathrm{BBB}}$ \\
\hline 6 & 162.57 & $-2.82^{\mathrm{BBB}}$ & 95.38 & -.64 & 142.04 & $-1.74^{\mathrm{BB}}$ & 91.65 & -.55 & 132.23 & $-2.72^{\mathrm{BBB}}$ & 143.07 & $-3.30^{\mathrm{BBB}}$ \\
\hline 12 & 221.09 & $-4.21^{\mathrm{BBB}}$ & 114.62 & -.62 & 148.98 & $-1.86^{\mathrm{BB}}$ & 104.39 & -.24 & 148.79 & $-4.09^{\mathrm{BBB}}$ & 157.51 & $-4.75^{\text {ВВВ }}$ \\
\hline 24 & 258.58 & $-6.30^{\mathrm{BBB}}$ & 118.38 & -.86 & 99.47 & -.03 & 91.15 & -.44 & 616.47 & $-7.11^{\mathrm{BBB}}$ & 622.07 & $-7.25^{\mathrm{BBB}}$ \\
\hline
\end{tabular}

For the notations see Table 3. 
Table 5

Out-of-sample forecast error statistics for Japan; Hodrick-Prescott filtered forecasts

\begin{tabular}{|c|c|c|c|c|c|c|c|c|c|c|c|c|}
\hline & \multicolumn{4}{|c|}{ g; real growth } & \multicolumn{4}{|c|}{$\pi ;$ inflation rate } & \multicolumn{4}{|c|}{$q$ : real exchange rate } \\
\hline & RMSE of & $D-M$ for & RMSE of & $D-M$ for & RMSE of & $D-M$ for & RMSE of & $D-M$ for & RMSE of & $D-M$ for & RMSE of & $D$-M for \\
\hline & $A R-X$ & $A R-X$ & $A R-X$ & $A R-X$ & $A R-X$ & $A R-X$ & $A R-X$ & $A R-X$ & $A R-X$ & $A R-X$ & $A R-X$ & $A R-X$ \\
\hline Period & against & $v s$. & against & vs. & against & vs. & against & vs. & against & vs. & against & vs. \\
\hline $1985: 8-2007: 1$ & $A R$ & $A R$ & VAR & $V A R$ & AR & $A R$ & $\begin{array}{l}V A R \\
(\%)\end{array}$ & $V A R$ & $A R$ & $A R$ & $\begin{array}{l}\text { VAR } \\
(\%)\end{array}$ & $V A R$ \\
\hline \multicolumn{13}{|l|}{ Forecast horizon } \\
\hline 1 & 80.31 & $-1.80^{* *}$ & 70.87 & $-3.19^{* * *}$ & 43.17 & $-6.80^{* * *}$ & 61.72 & $-4.37^{* * *}$ & 200.00 & $-5.47^{\mathrm{BBB}}$ & 195.65 & $-5.26^{\mathrm{BBB}}$ \\
\hline 3 & 73.56 & $-2.52^{* * *}$ & 81.98 & $-2.00^{* *}$ & 61.48 & $-4.38^{* * * *}$ & 66.37 & $-4.05^{* * * *}$ & 229.75 & $-5.18^{\mathrm{BBB}}$ & 238.20 & $-5.44^{\text {BВB }}$ \\
\hline 6 & 102.85 & -.26 & 88.06 & $-1.33^{*}$ & 85.16 & -1.18 & 86.84 & -1.13 & 124.78 & $-1.44^{\mathrm{B}}$ & 126.20 & $-1.51^{\mathrm{B}}$ \\
\hline $\begin{array}{c}0 \\
12\end{array}$ & 135.03 & $-2.83^{\mathrm{BBB}}$ & 103.28 & -.33 & 85.88 & $-1.34^{*}$ & 67.56 & $-4.14^{* * * *}$ & 80.10 & $-2.26^{* *}$ & 81.63 & $-2.09^{* * *}$ \\
\hline 24 & 223.46 & $-7.20^{\mathrm{BBB}}$ & 150.94 & $-3.97^{\text {BBB }}$ & 102.09 & -.21 & 55.20 & $-6.05^{* * *}$ & 54.81 & $-3.01^{* * * *}$ & 62.02 & $-2.57^{* * * *}$ \\
\hline \multicolumn{13}{|l|}{$\begin{array}{c}\text { Period } \\
1985: 8-1998: 12\end{array}$} \\
\hline \multicolumn{13}{|l|}{ Forecast horizon } \\
\hline 1 & 66.24 & $-2.96^{* * * *}$ & 59.37 & $-4.24^{* * * *}$ & 27.17 & $-9.07^{* * * *}$ & 46.31 & $-5.47^{* * *}$ & 92.00 & -.30 & 95.92 & -.20 \\
\hline 3 & 42.40 & $-4.68^{* * *}$ & 51.08 & $-4.26^{* * *}$ & 37.74 & $-6.55^{* * *}$ & 45.80 & $-5.37^{* * *}$ & 129.37 & $-1.93^{\mathrm{BB}}$ & 136.79 & $-2.48^{\mathrm{BB}}$ \\
\hline 6 & 72.50 & $-2.17^{* *}$ & 62.73 & $-3.49^{* * *}$ & 39.71 & $-6.47^{* * *}$ & 44.28 & $-6.17^{* * *}$ & 51.28 & $-6.88^{* * * *}$ & 52.19 & $-6.76^{* * * *}$ \\
\hline 12 & 102.48 & -.15 & 74.76 & $-2.19^{* *}$ & 60.00 & $-3.61^{* * *}$ & 48.65 & $-5.97^{* * *}$ & 48.66 & $-9.22^{* * *}$ & 49.69 & $-9.11^{* * * *}$ \\
\hline 24 & 178.67 & $-3.81^{\mathrm{BBB}}$ & 108.50 & -.61 & 86.75 & -1.18 & 45.66 & $-7.07^{* * *}$ & 22.87 & $-5.56^{* * *}$ & 26.25 & $-5.12^{* * *}$ \\
\hline
\end{tabular}

For the notations see Table 3. 

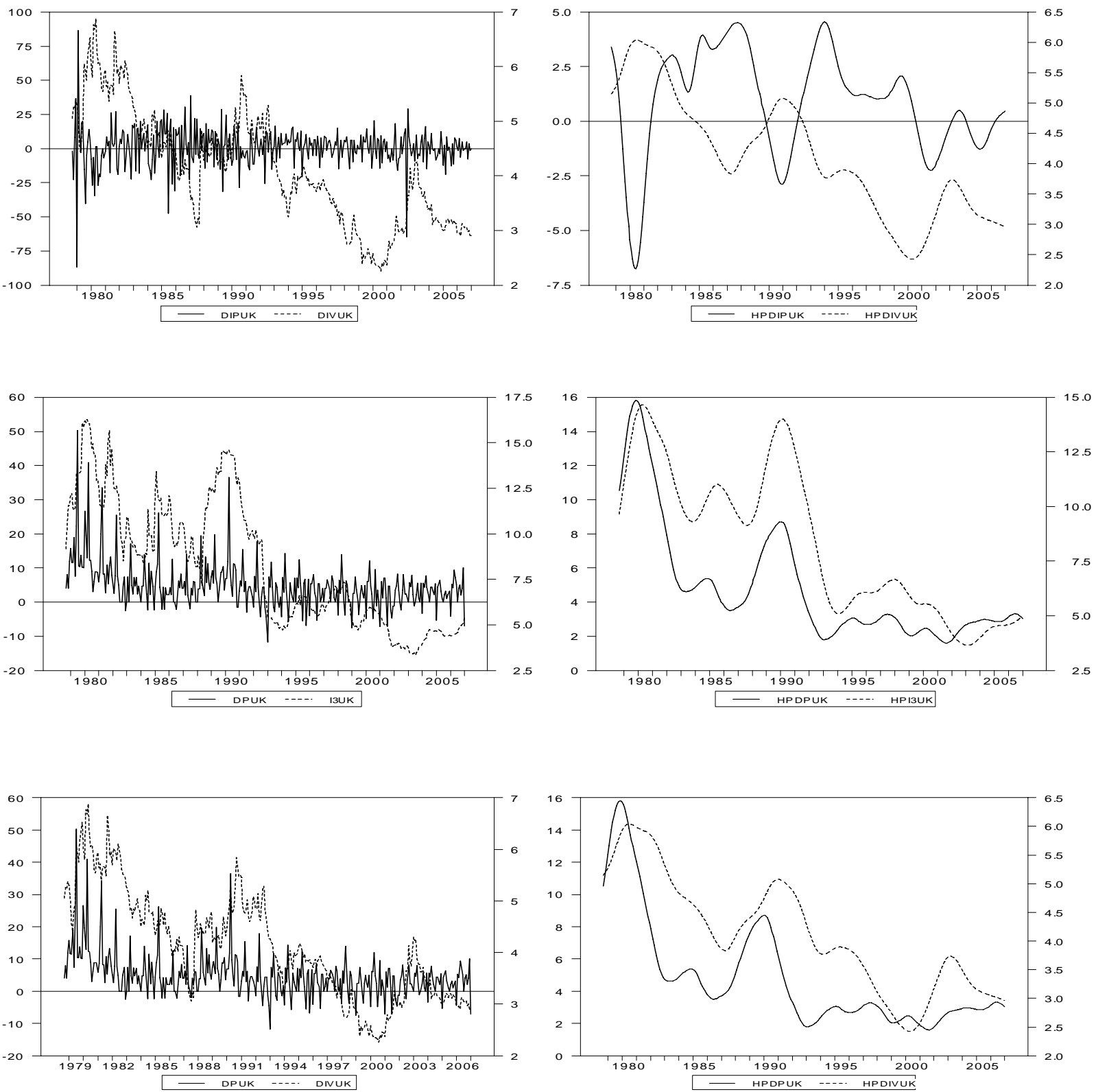

Figure 1

Pair-wise comparisons of the time series of the contemporaneous values of the macro variables and the financial market variables based on the system of equations (12) in the text. Data for the U.K.

All data are in \%-values except the real exchange rate which is in log levels; DIPUK = real growth (annualized change in the log of industrial production index), DIVUK = dividend yield, DPUK = inflation (annualized change in the log of Consumer Price Index), I3UK = the 3-month nominal interest rate, RERUK = real exchange rate, and DDIVUK = the dividend yield spread (foreign (U.S.) minus domestic (U.K) yield). Left panels are for the raw time series data and right panels for the time-varying trends extracted from the raw data using a Hodrick - Prescott (1997) filter with a lambda value 1600

Fig 1 continues 

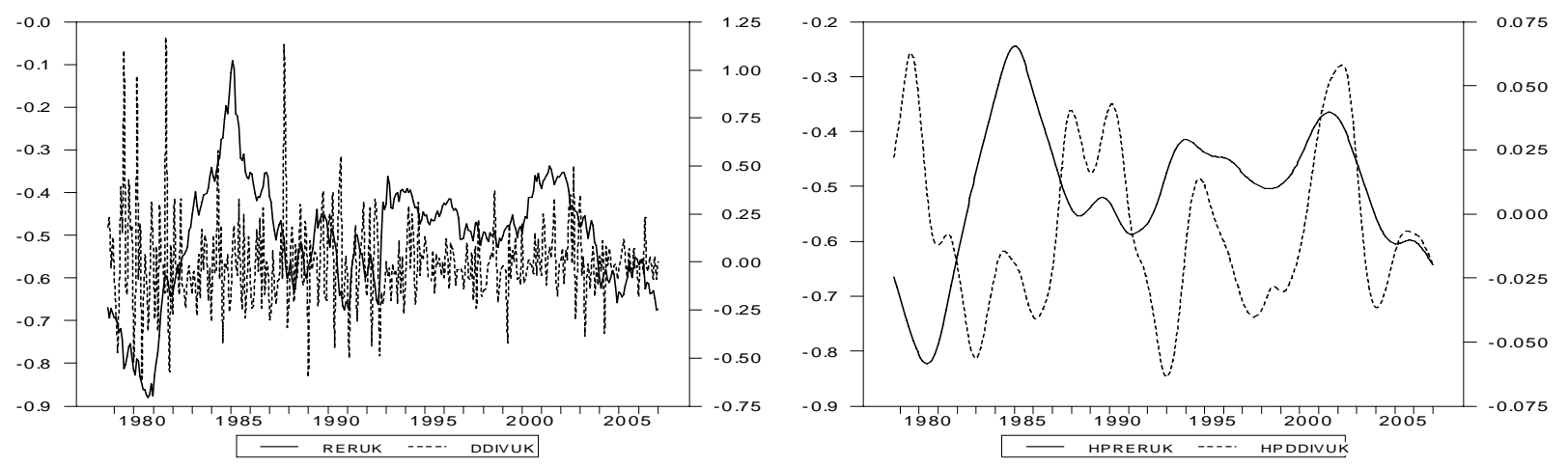

Figure 1 continued 

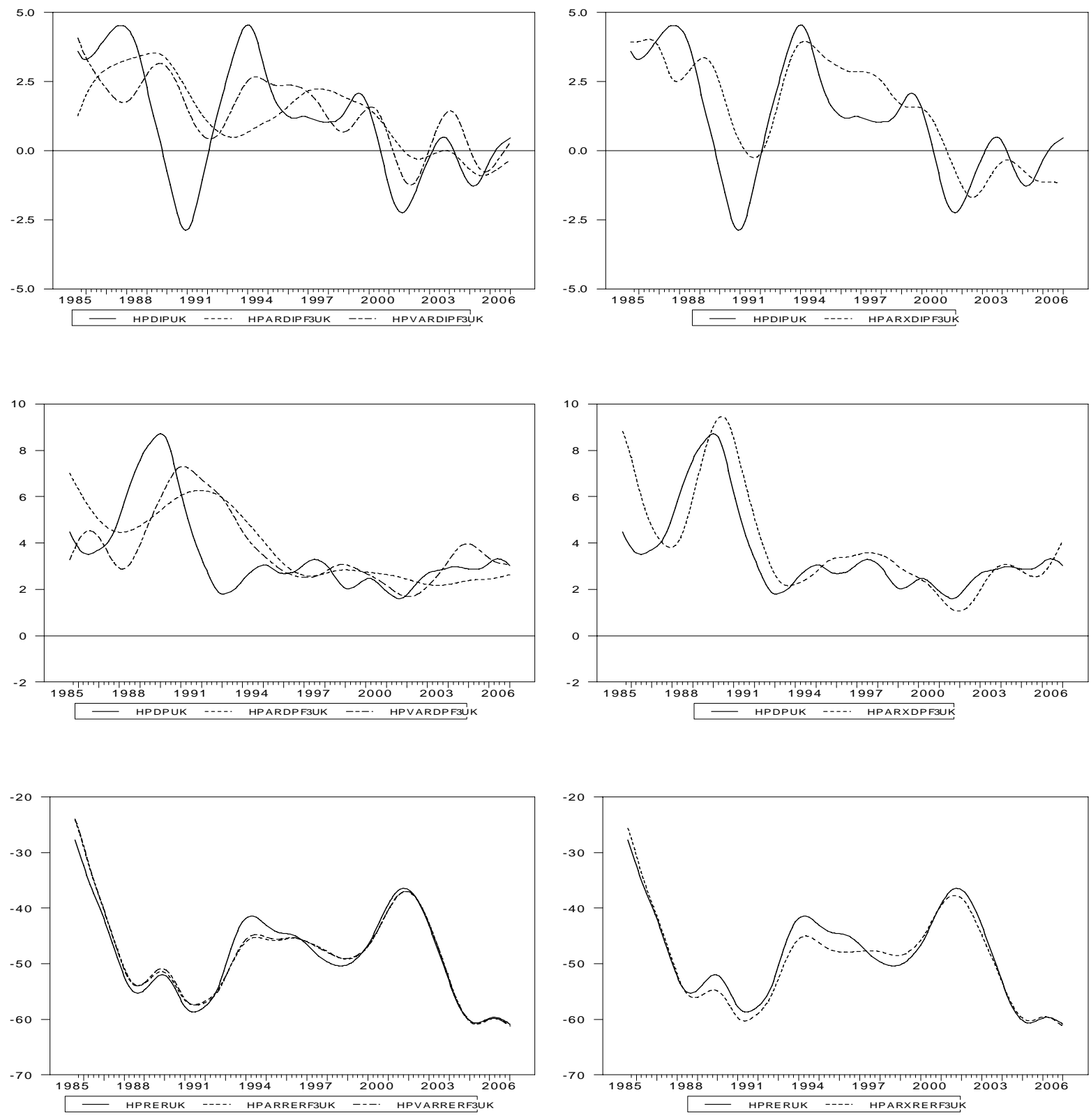

3-month horizon

\section{Figure 2}

Pair-wise comparisons of the time-varying trends in the out-of-sample forecasts of macro-economy. Results for the U.K. at 3-and 24-month forecast horizons. In the left-hand are the forecasts from $\operatorname{AR}(2)$ and VAR(2) benchmark models with the actual future values, and in the right-hand are the forecasts from AR-X-type estimation for the individual equations of system (14) given in the text and the actual future values.

For comparison the left- and right-hand panels use the same scale pair-wise. In both panels the Hodrick-Prescott filtered forecasts (with a lambda value 1600) and actual values are plotted. HPARDIPF\#UK, HPARDPF\#UK, and HPARRERF\#UK refer to the forecast values for real growth, inflation and real exchange rate, respectively, from the AR(2)-model; HPVARDIPF\#UK, HPVARDPF\#UK, and HPVARRERF\#UK to the corresponding forecast values from the VAR(2)-model. HPARXDIPF\#UK, HPARXDPF\#UK, and HPARXRERF\#UK are the corresponding forecast values from the AR-X-type model based on system (14) in the text, and \# refers to the forecast horizon. HPDIPUK, HPDPUK and HPRERUK are the (filtered) actual future values of real growth, inflation and real exchange rate.

Fig 2 continues 

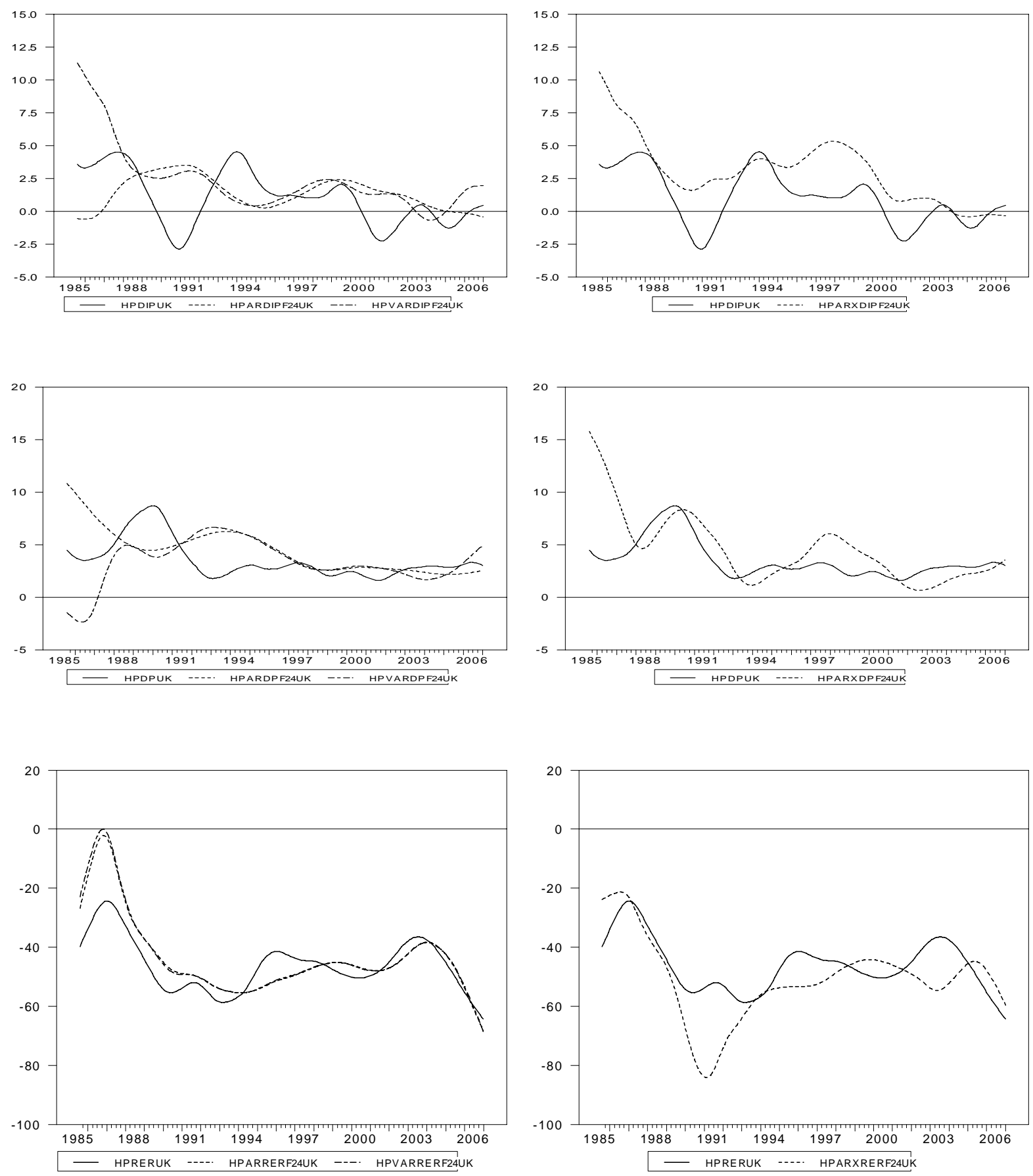

\section{4-month horizon}

Figure 2 continued 

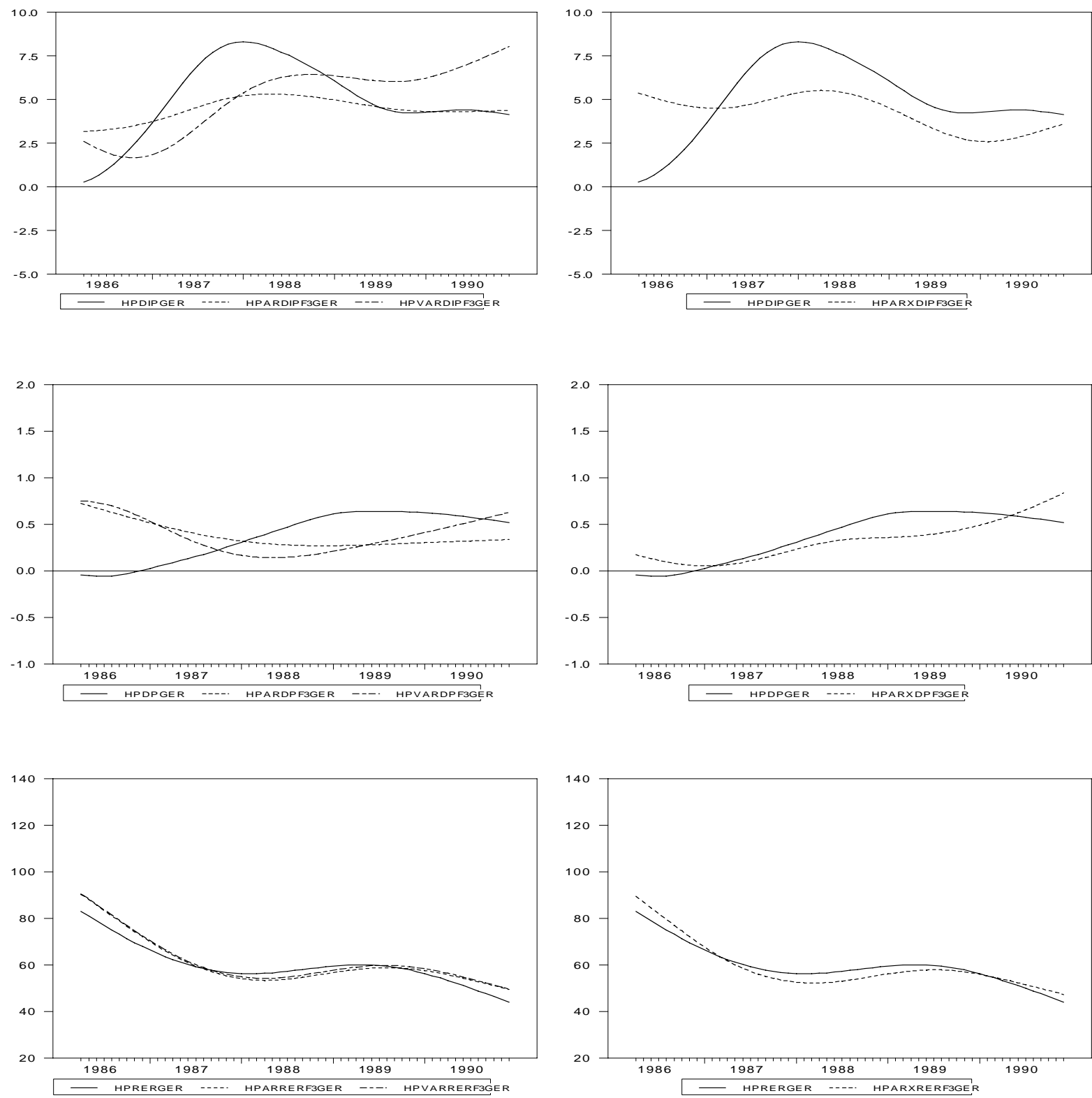

3-month horizon

Figure 3

Pair-wise comparisons of the time-varying trends in the out-of-sample forecasts of macro-economy. Results for Germany at 3-and 24-month forecast horizons. In the left-hand panel the forecasts from $\operatorname{AR}(2)$ and VAR(2) benchmark models together with the actual future values are plotted, and in the right-hand panel are the forecasts from AR-X-type estimation for the individual equations of system (14) given in the text and the actual future values.

For comparison the left- and right-hand panels use the same scale pair-wise. In both panels the Hodrick-Prescott filtered forecasts (with a lambda value 1600) and actual values are plotted. HPARDIPF\#GER, HPARDPF\#GER, and HPARRERF\#GER refer to the forecast values for real growth, inflation and real exchange rate, respectively, from the AR(2)-model; HPVARDIPF\#GER, HPVARDPF\#GER, and HPVARRERF\#GER to the corresponding forecast values from the VAR(2)-model. HPARXDIPF\#GER, HPARXDPF\#GER, and HPARXRERF\#GER are the corresponding forecast values from the AR-X-type model based on system (14) in the text, and \# refers to the forecast horizon. HPDIPGER, HPDPGER and HPRERGER are the (filtered) actual future values of real growth, inflation and real exchange rate.

Fig 3 continues 

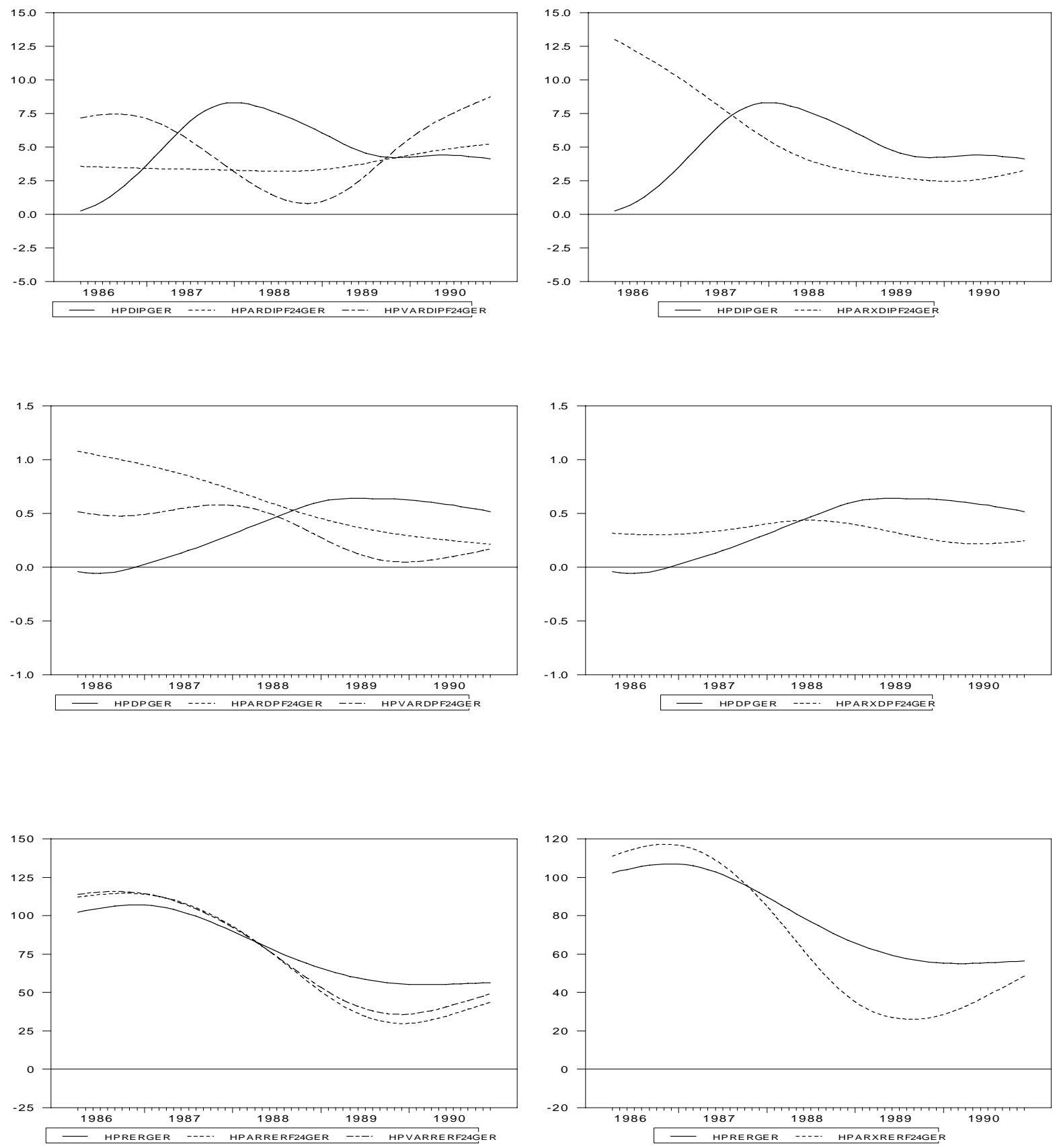

\section{4-month horizon}

Figure 3 continued 

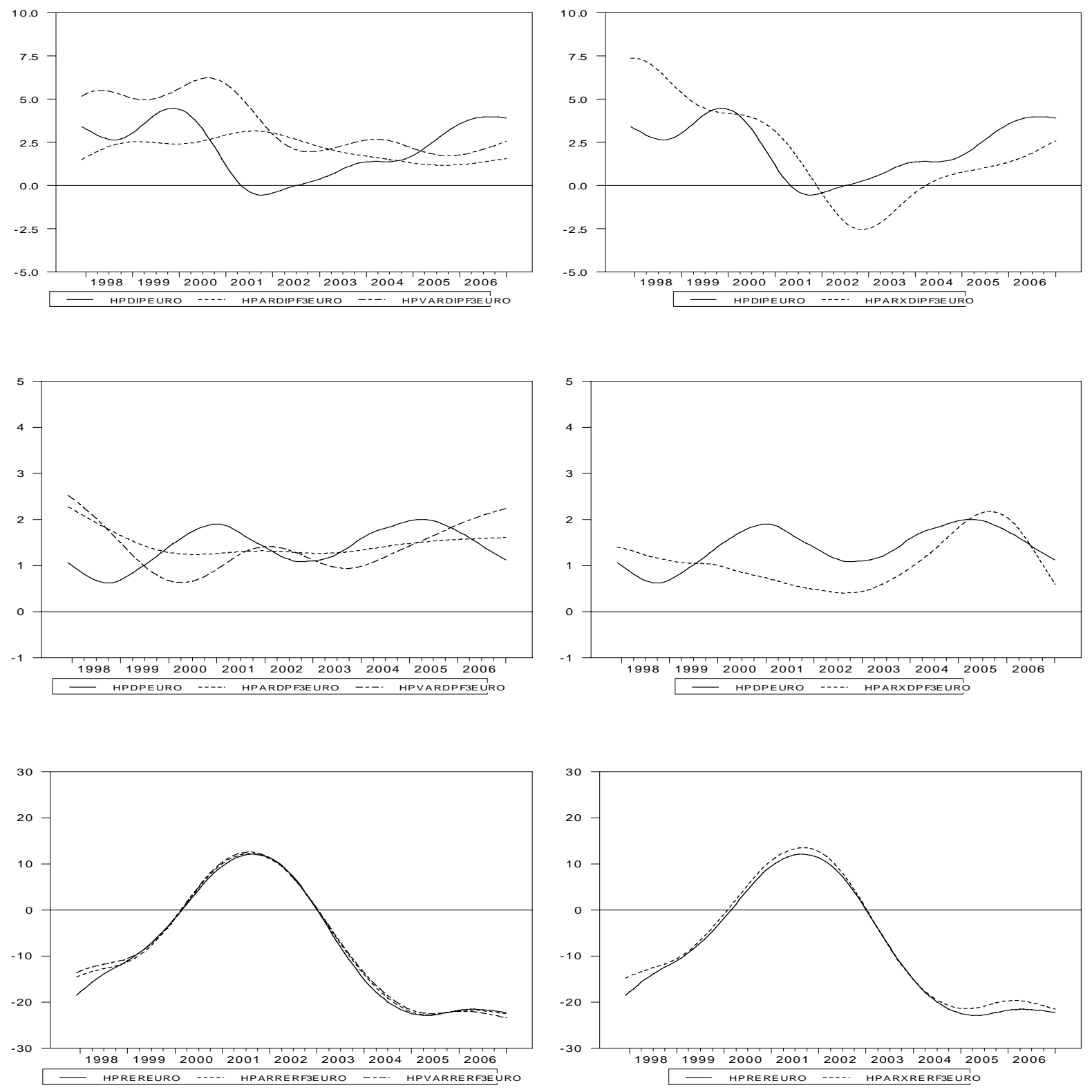

3-month horizon

\section{Figure 4}

Pair-wise comparisons of the time-varying trends in the out-of-sample forecasts of macro-economy. Results for the Euro-zone at 3-and 24-month forecast horizons. In the left-hand panel the forecasts from $A R(2)$ and VAR(2) benchmark models together with the actual future values are plotted, and in the right-hand panel are the forecasts from AR-X-type estimation for the individual equations of system (14) given in the text and the actual future values.

For comparison the left- and right-hand panels use the same scale pair-wise. In both panels the Hodrick-Prescott filtered forecasts (with a lambda value 1600) and actual values are plotted. HPARDIPF\#EURO, HPARDPF\#EURO, and HPARRERF\#EURO refer to the forecast values for real growth, inflation and real exchange rate, respectively, from the AR(2)-model; HPVARDIPF\#EURO, HPVARDPF\#EURO, and HPVARRERF\#EURO to the corresponding forecast values from the VAR(2)-model. HPARXDIPF\#EURO, HPARXDPF\#EURO, and HPARXRERF\#EURO are the corresponding forecast values from the AR-X-type model based on system (14) in the text, and \# refers to the forecast horizon. HPDIPEURO HPDPEURO and HPREREURO are the (filtered) actual future values of real growth, inflation and real exchange rate.

Fig 4 continues 

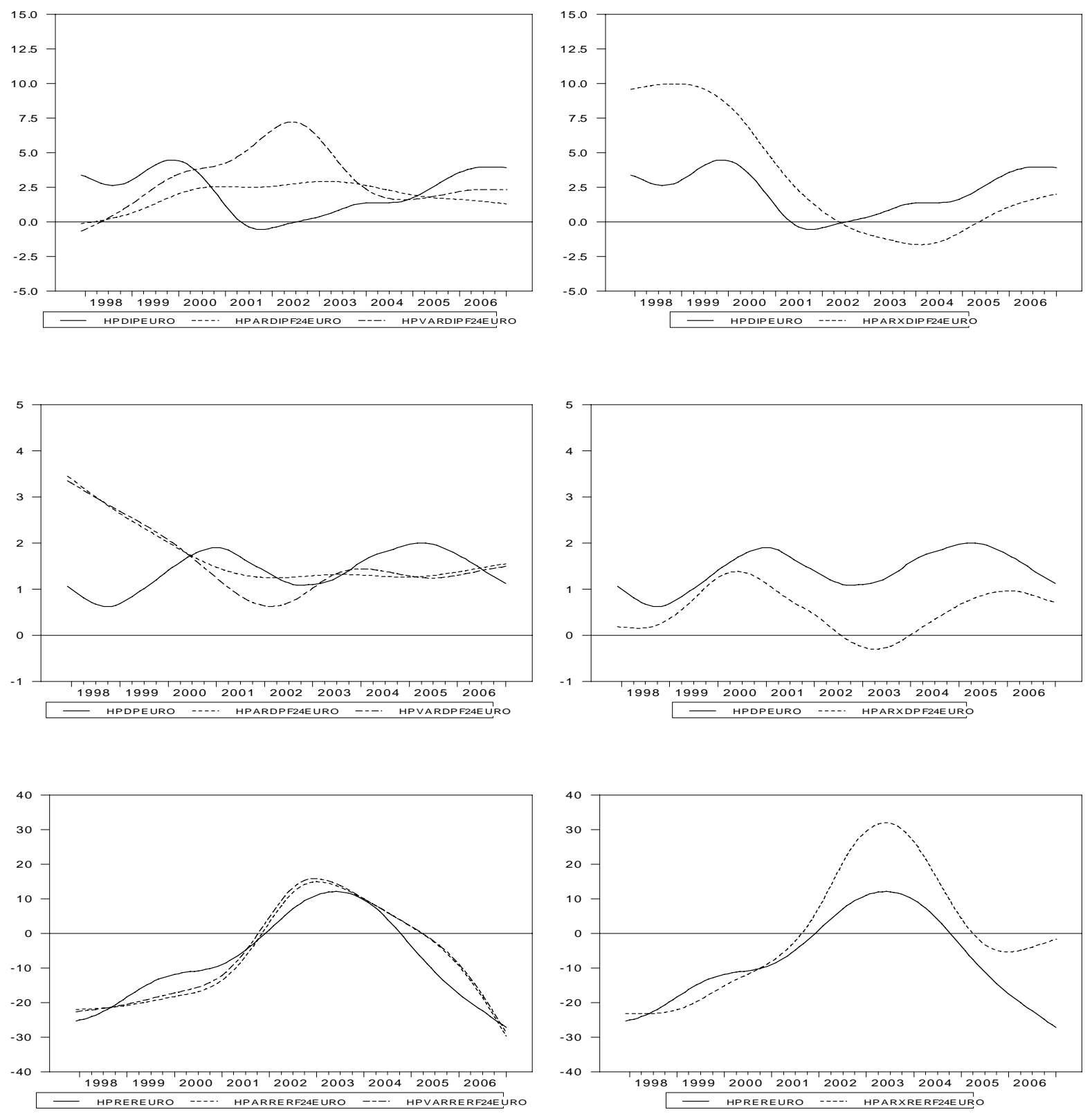

24-month horizon

Figure 4 continued 

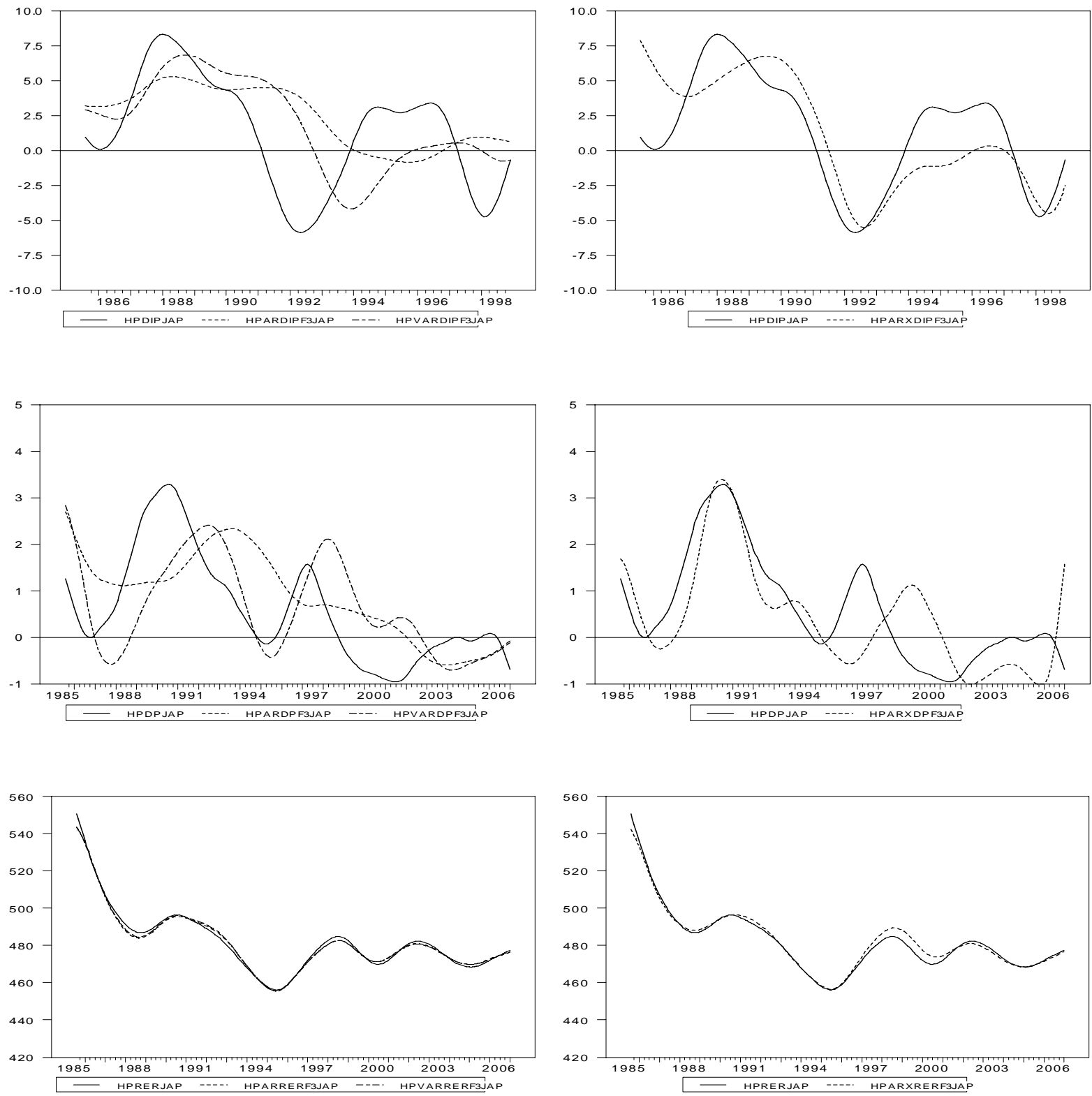

3-month horizon

\section{Figure 5}

Pair-wise comparisons of the time-varying trends in the out-of-sample forecasts of macro-economy. Results for Japan at 3-and 24-month forecast horizons. In the left-hand panel the forecasts from $\operatorname{AR}(2)$ and $\operatorname{VAR}(2)$ benchmark models together with the actual future values are plotted, and in the right-hand panel are the forecasts from AR-X-type estimation for the individual equations of system (14) given in the text and the actual future values.

For comparison the left- and right-hand panels use the same scale pair-wise. In both panels the Hodrick-Prescott filtered forecasts (with a lambda value 1600) and actual values are plotted. ARDIPF\#JAP, ARDPF\#JAP, and ARRERF\#JAP refer to the forecast values for real growth, inflation and real exchange rate, respectively, from the AR(2)-model; VARDIPF\#JAP, VARDPF\#JAP, and VARRERF\#JAP to the corresponding forecast values from the VAR(2)-model. ARXDIPF\#JAP, ARXDPF\#JAP, and ARXRERF\#JAP are the corresponding forecast values from the AR-X-type model based on system (14) in the text, and \# refers to the forecast horizon. HPDIPJAP, HPDPJAP and HPRERJAP are the (filtered) actual future values of real growth, inflation and real exchange rate, and \# refers to the forecast horizon.

Fig 5 continues 

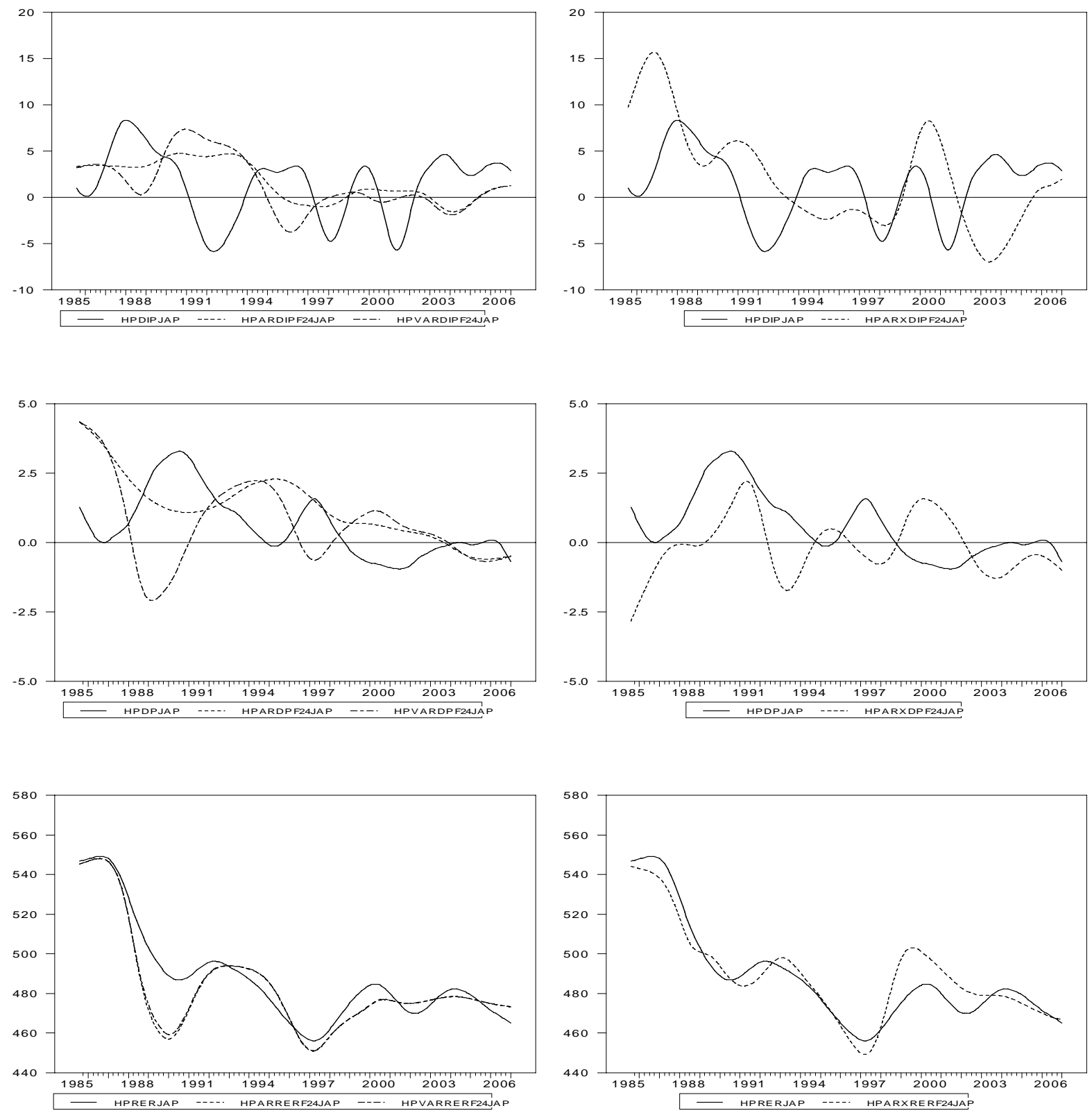

\section{4-month horizon}

Figure 5 continued 


\section{Appendix B: Additional figures and tables}
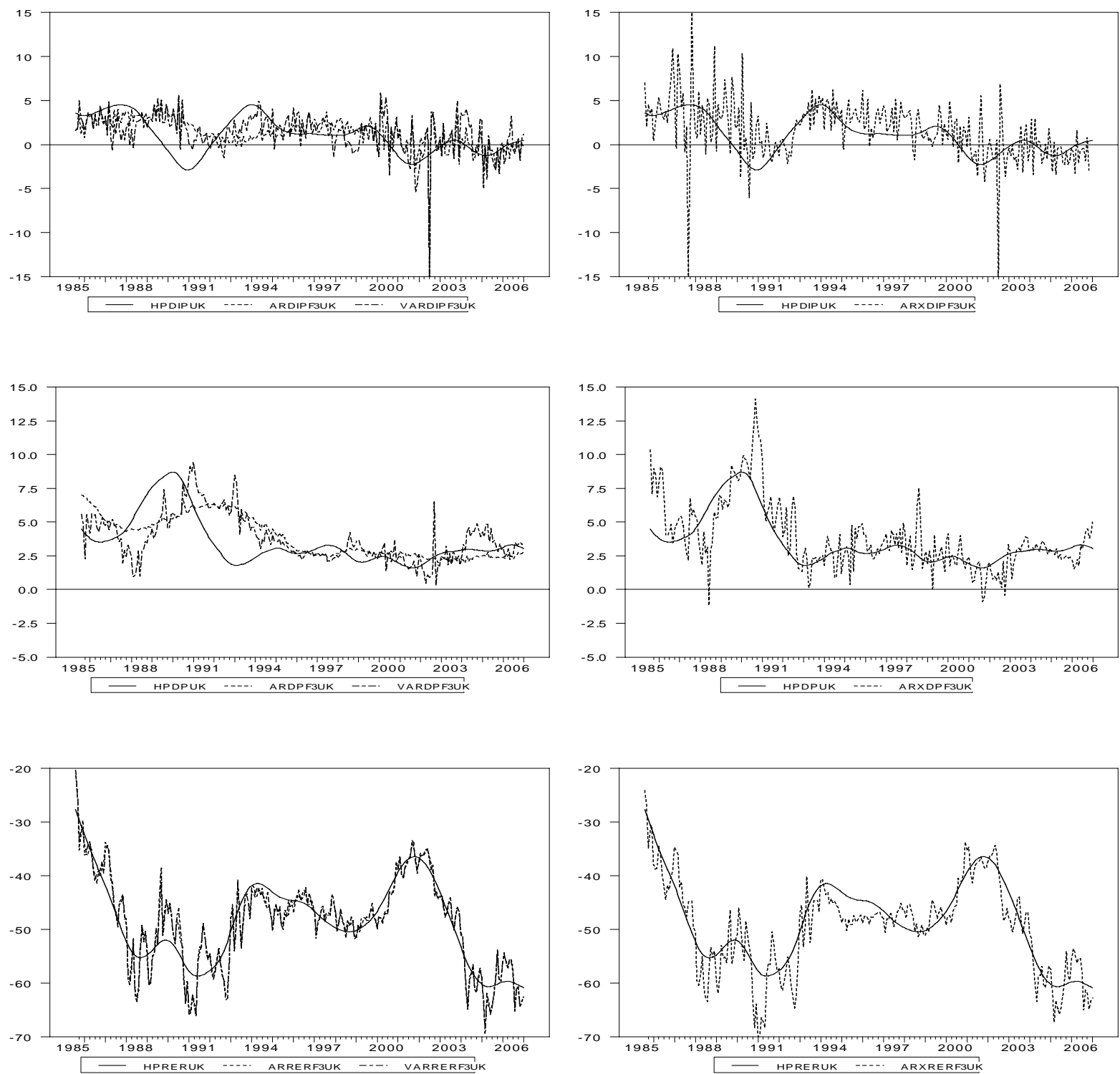

3-month horizon

\section{Figure B1}

Pair-wise comparisons of the actual out-of-sample forecasts of macro-economy. Results for the U.K. at 3-and 24-month forecast horizons for actual, unfiltered observations. In the left-hand are the forecasts from $\operatorname{AR}(2)$ and $\operatorname{VAR}(2)$ benchmark models with the (HP-filtered) actual future values, and in the right-hand are the forecasts from AR-X-type estimation for the individual equations of system (14) given in the text and the (HP-filtered) actual future values.

For comparison the left- and right-hand panels use the same scale pair-wise. ARDIPF\#UK, ARDPF\#UK, and ARRERF\#UK refer to the forecast values for real growth, inflation and real exchange rate, respectively, from the AR(2)-model; VARDIPF\#UK, VARDPF\#UK, and VARRERF\#UK to the corresponding forecast values from the VAR(2)-model. ARXDIPF\#UK, ARXDPF\#UK, and ARXRERF\#UK are the corresponding forecast values from the AR-X-type model based on system (14) in the text, and \# refers to the forecast horizon. HPDIPUK, HPDPUK and HPRERUK are the (filtered) actual future values of real growth, inflation and real exchange rate.

Fig B1 continues 

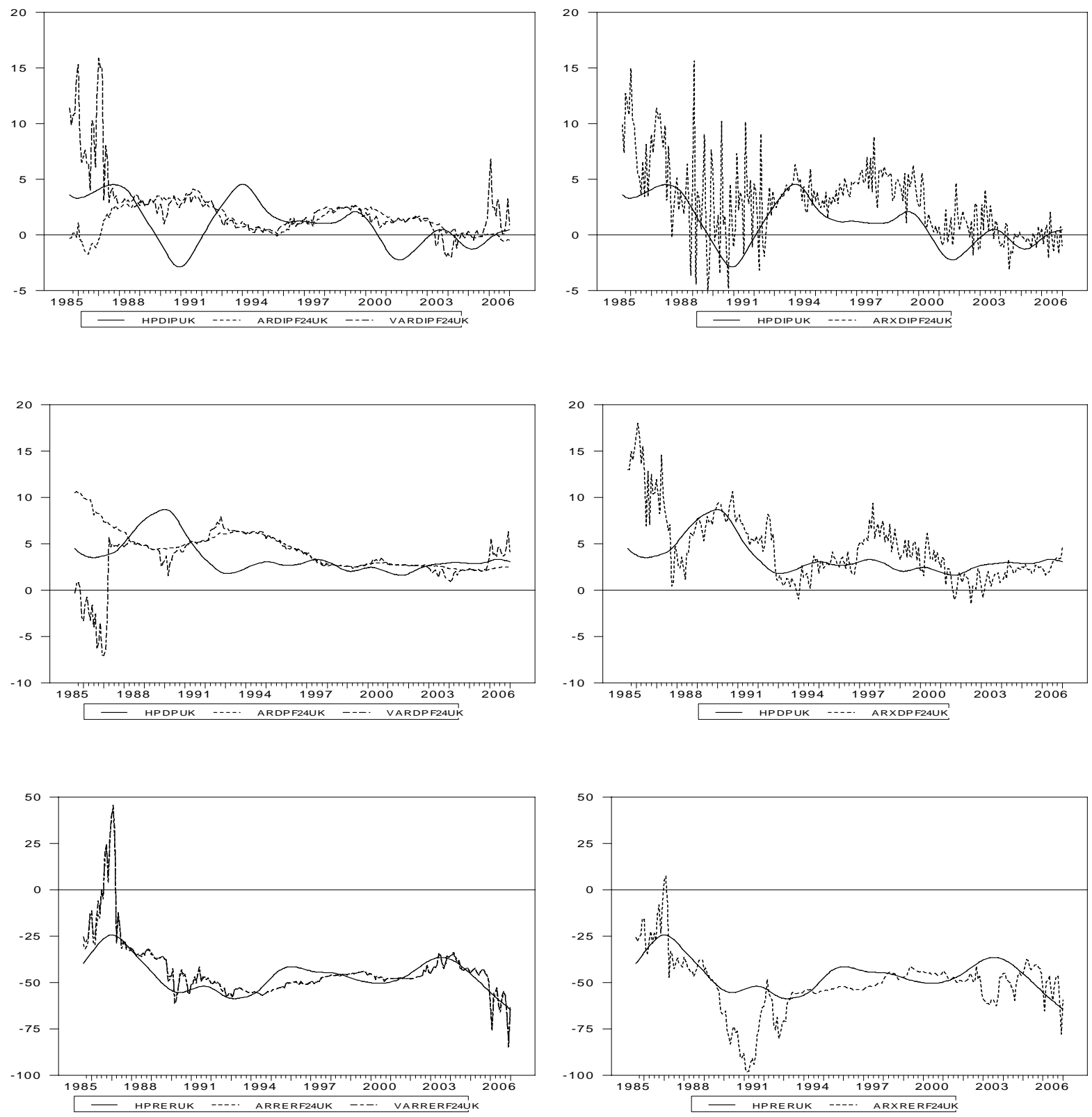

\section{4-month horizon}

Figure B1 continued 

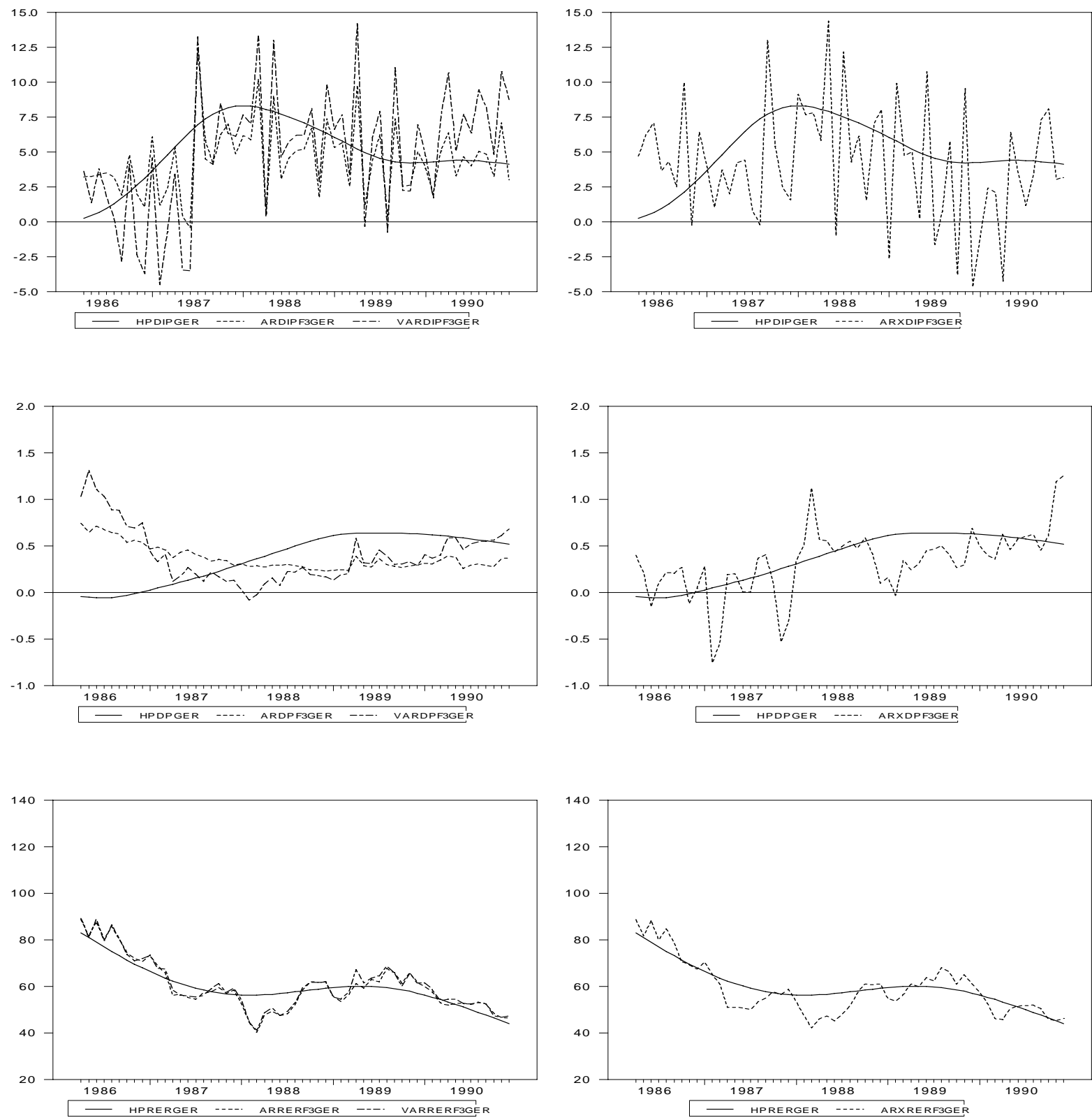

3-month horizon

\section{Figure B2}

Pair-wise comparisons of actual out-of-sample forecasts of macro-economy. Results for Germany at 3-and 24-month forecast horizons for unfiltered observations. In the left-hand are the forecasts from AR(2) and VAR(2) benchmark models with the (HP-filtered) actual future values, and in the righthand are the forecasts from AR-X-type estimation for the individual equations of system (14) given in the text and the (HP-filtered) actual future values.

For comparison the left- and right-hand panels use the same scale pair-wise. ARDIPF\#GER, ARDPF\#GER, and ARRERF\#GER refer to the forecast values for real growth, inflation and real exchange rate, respectively, from the AR(2)-model; VARDIPF\#GER, VARDPF\#GER, and VARRERF\#GER to the corresponding forecast values from the VAR(2)-model. ARXDIPF\#GER, ARXDPF\#GER, and ARXRERF\#GER are the corresponding forecast values from the AR-X-type model based on system (14) in the text, and \# refers to the forecast horizon. HPDIPGER, HPDPGER and HPRERGER are the (filtered) actual future values of real growth, inflation and real exchange rate.

Fig B2 continues 

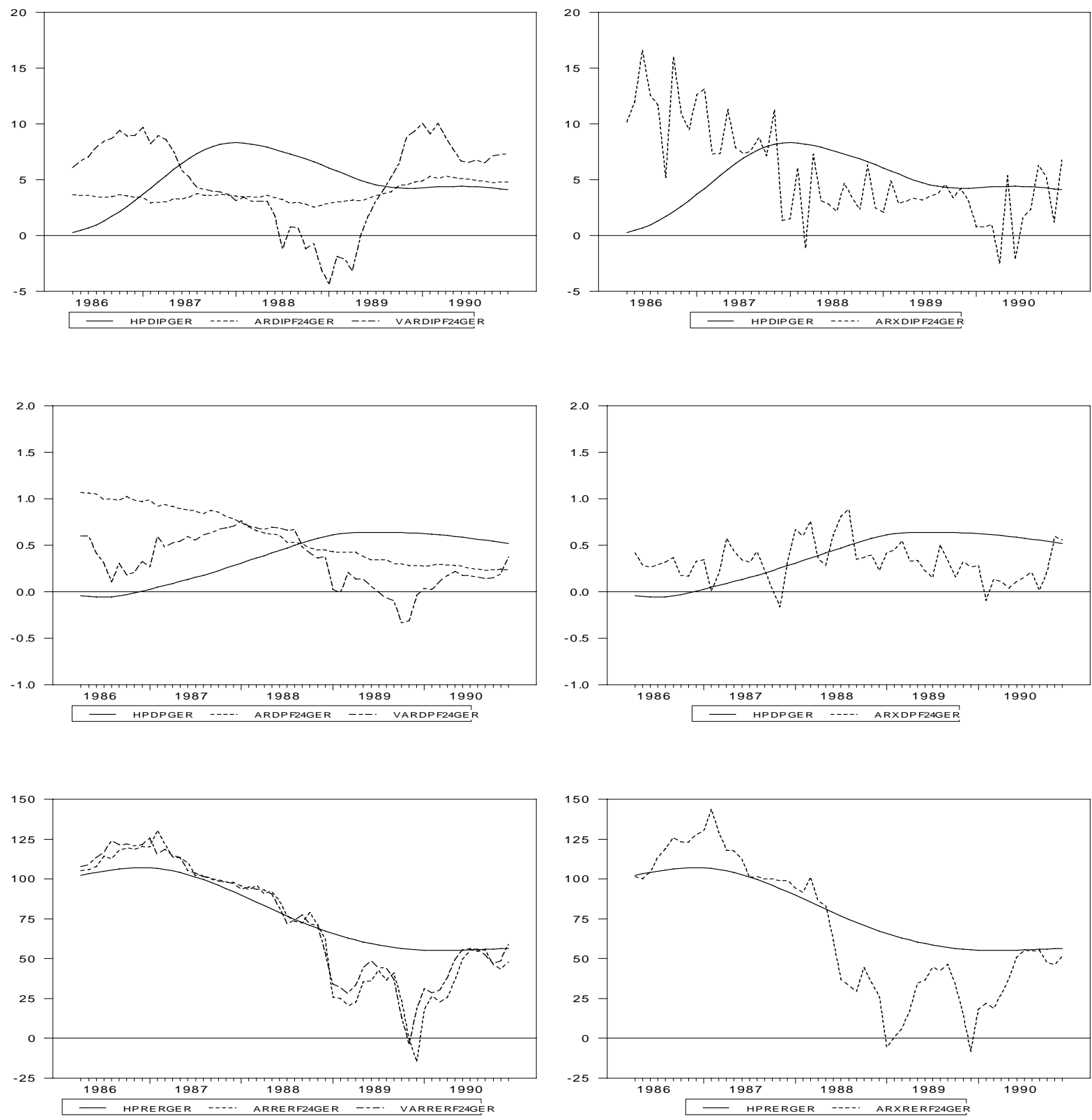

24-month horizon

Figure B2 continued 

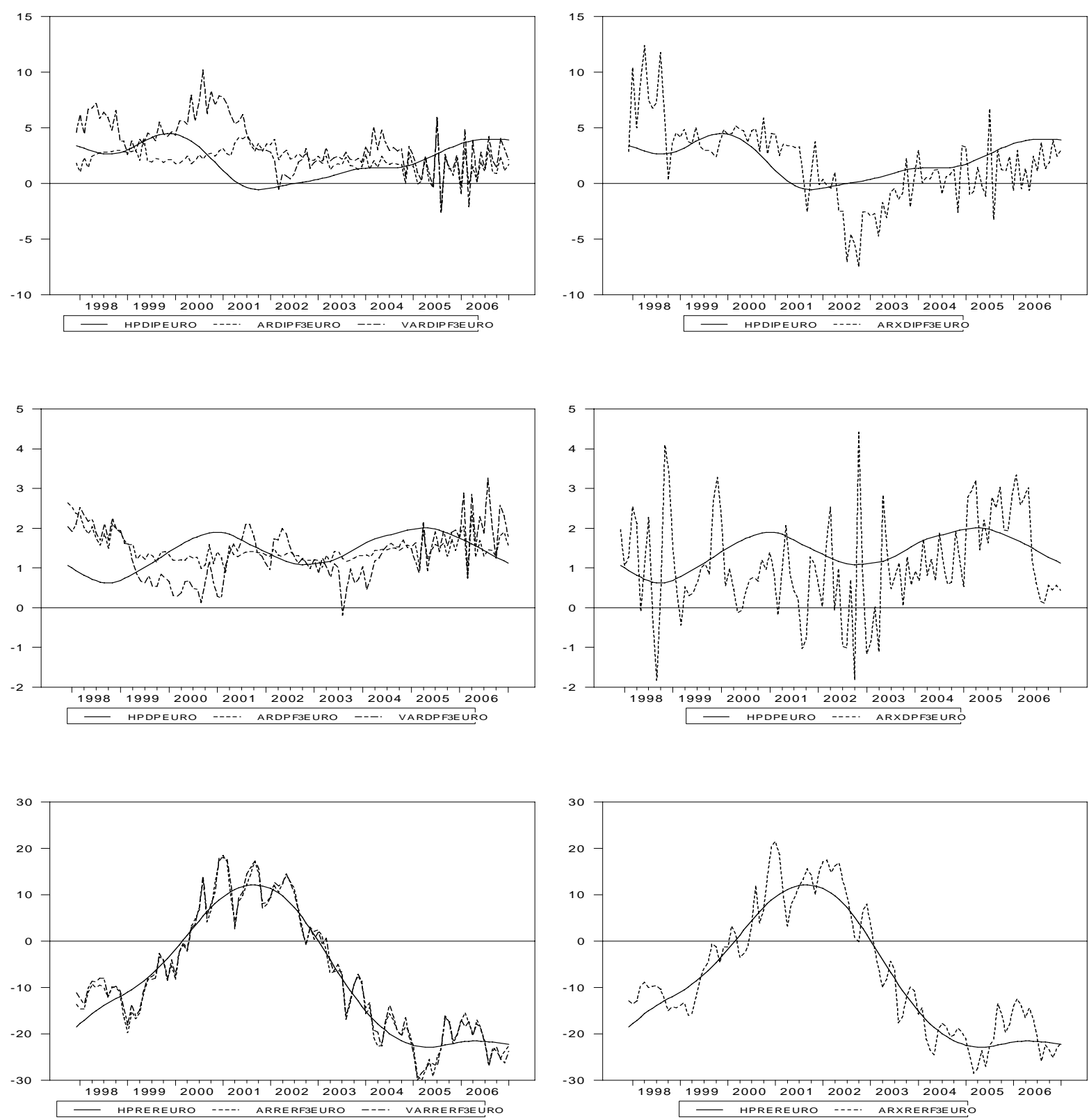

3-month horizon

\section{Figure B3}

Pair-wise comparisons of the actual out-of-sample forecasts of macro-economy. Results for the Eurozone data at 3-and 24-month forecast horizons for unfiltered observations. In the left-hand are the forecasts from $A R(2)$ and VAR(2) benchmark models with the (HP-filtered) actual future values, and in the right-hand are the forecasts from AR-X-type estimation for the individual equations of system (14) given in the text and the (HP-filtered) actual future values.

For comparison the left- and right-hand panels use the same scale pair-wise. ARDIPF\#EURO, ARDPF\#EURO, and ARRERF\#EURO refer to the forecast values for real growth, inflation and real exchange rate, respectively, from the AR(2)-model; VARDIPF\#EURO, VARDPF\#EURO, and VARRERF\#EURO to the corresponding forecast values from the VAR(2)-model. ARXDIPF\#EURO, ARXDPF\#EURO, and ARXRERF\#EURO are the corresponding forecast values from the AR-X-type model based on system (14) in the text, and \# refers to the forecast horizon. HPDIPEURO, HPDPEURO and HPREREURO are the (filtered) actual future values of real growth, inflation and real exchange rate.

Fig B3 continues 

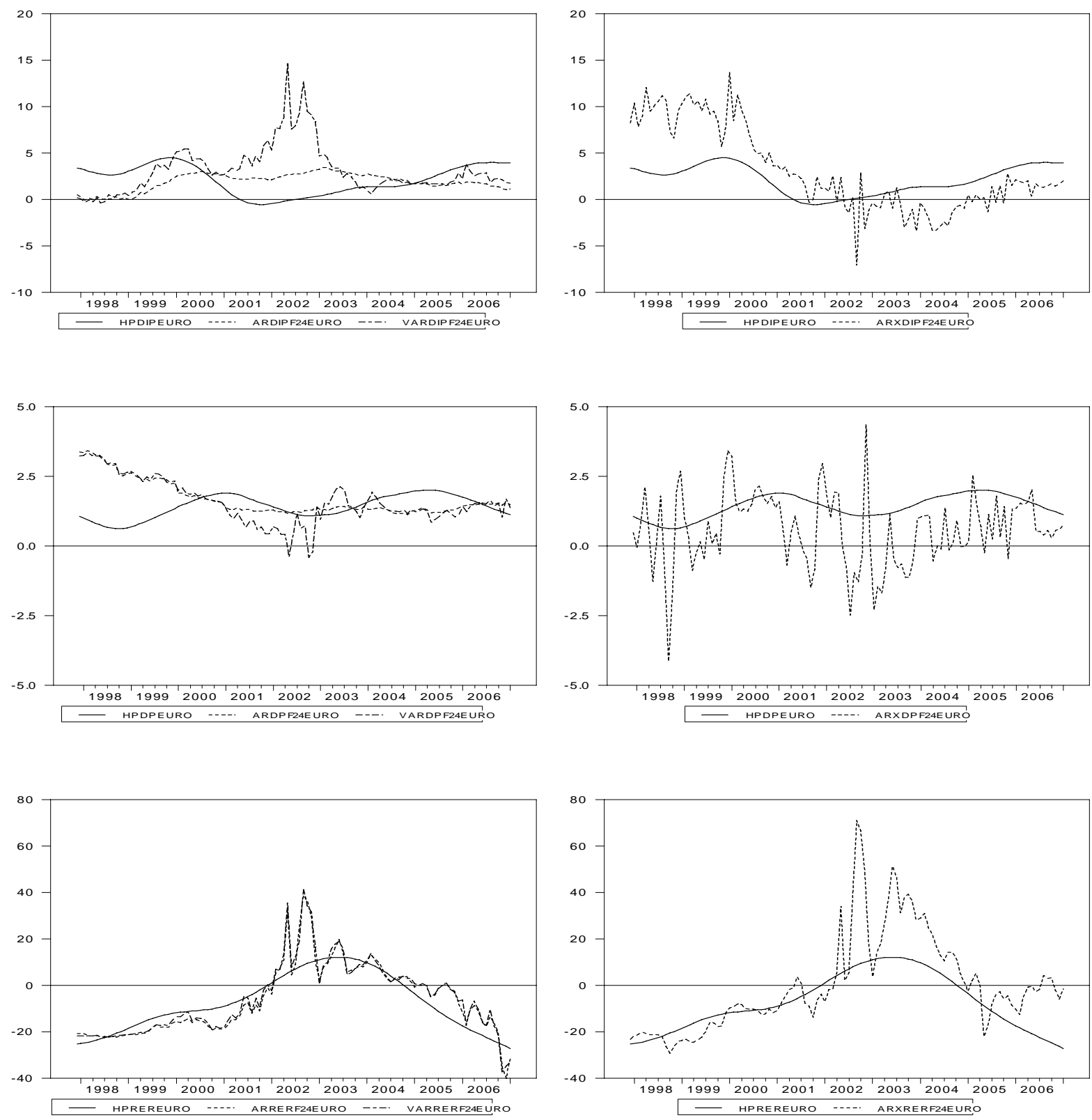

\section{4-month horizon}

\section{Figure B3 continued}



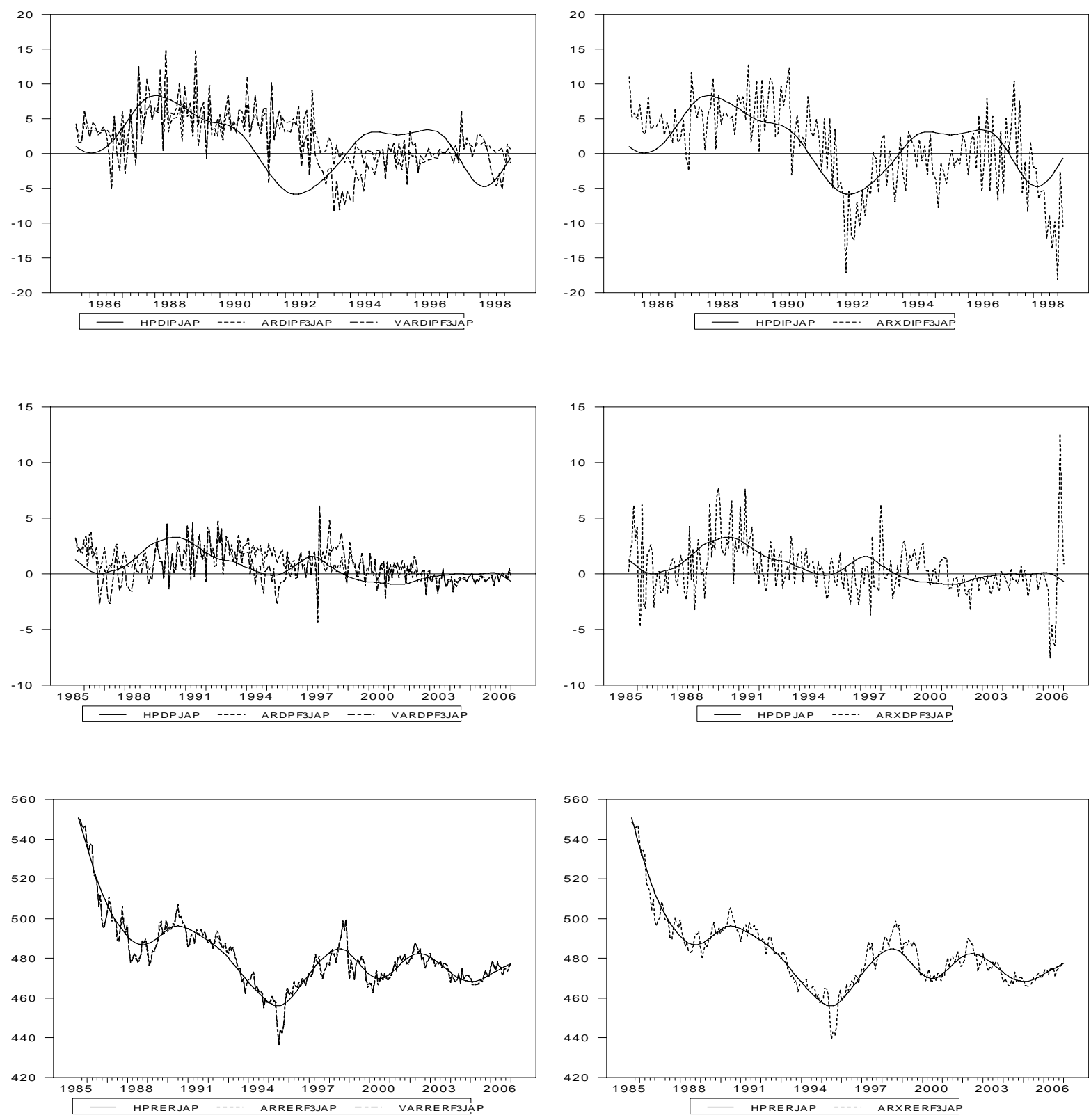

3-month horizon

\section{Figure B4}

Pair-wise comparisons of the actual out-of-sample forecasts of macro-economy. Results for Japan at 3-and 24-month forecast horizons for unfiltered observations. In the left-hand are the forecasts from AR(2) and VAR(2) benchmark models with the (HP-filtered) actual future values, and in the righthand are the forecasts from AR-X-type estimation for the individual equations of system (14) given in the text and the (HP-filtered) actual future values.

For comparison the left- and right-hand panels use the same scale pair-wise. ARDIPF\#JAP, ARDPF\#JAP, and ARRERF\#JAP refer to the forecast values for real growth, inflation and real exchange rate, respectively, from the AR(2)-model; VARDIPF\#JAP, VARDPF\#JAP, and VARRERF\#JAP to the corresponding forecast values from the VAR(2)-model. ARXDIPF\#JAP, ARXDPF\#JAP, and ARXRERF\#JAP are the corresponding forecast values from the AR-X-type model based on system (14) in the text. HPDIPJAP, HPDPJAP and HPRERJAP are the (filtered) actual future values of real growth, inflation and real exchange rate, and \# refers to the forecast horizon.

Fig B4 continues 

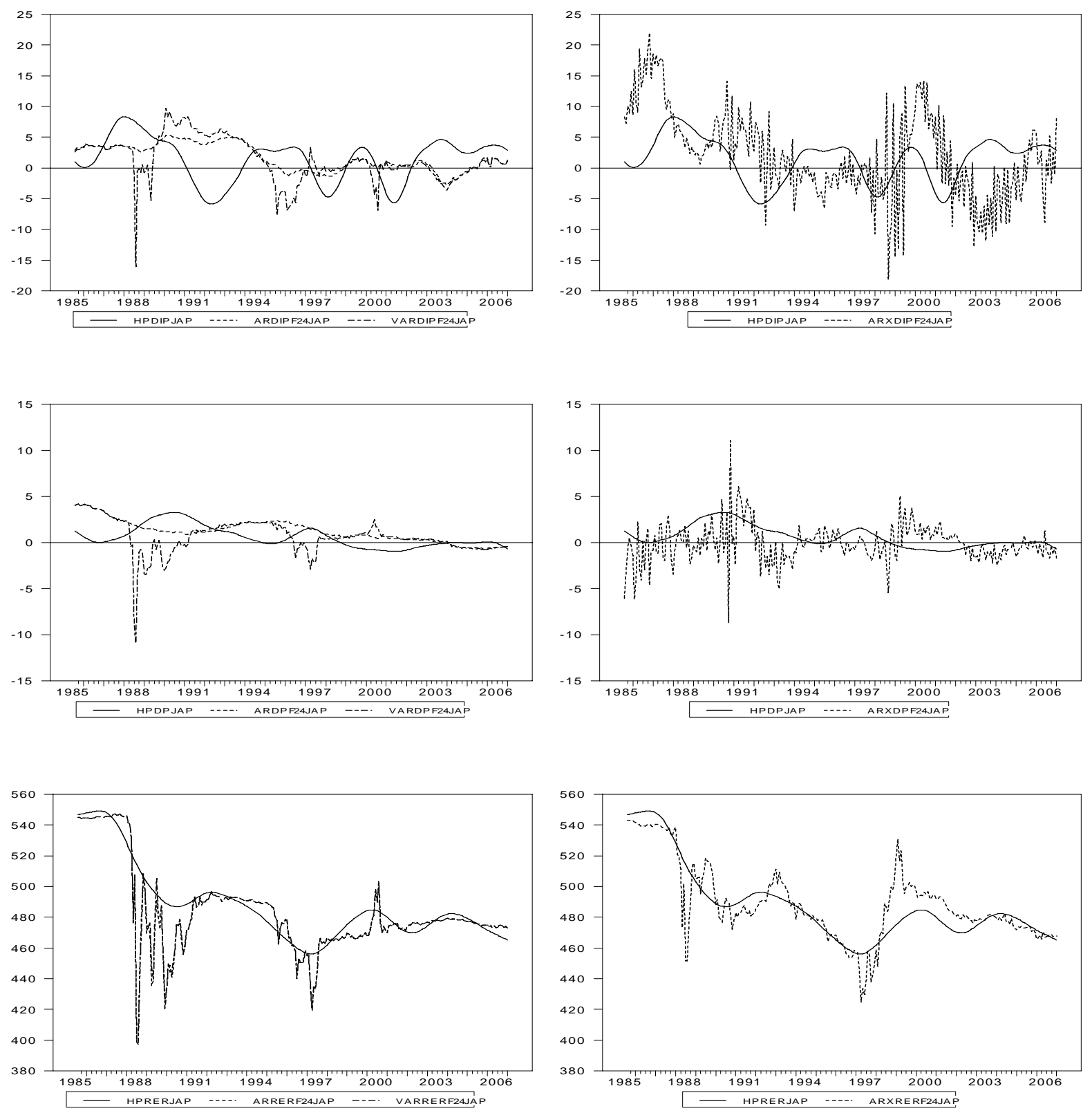

\section{4-month horizon}

Figure B4 continued 


\section{Table B1}

Out-of-sample forecast error statistics for the U.K.; unfiltered forecasts

\begin{tabular}{|c|c|c|c|c|c|c|c|c|c|c|c|c|}
\hline \multirow[b]{2}{*}{$\begin{array}{c}\text { Period } \\
\text { 1985:8 - 2007:1 } \\
\text { Forecast horizon }\end{array}$} & \multicolumn{4}{|c|}{ g; real growth } & \multicolumn{4}{|c|}{$\pi ;$ inflation rate } & \multicolumn{4}{|c|}{$q$ : real exchange rate } \\
\hline & $\begin{array}{c}\text { RMSE of } \\
\text { AR-X } \\
\text { against } \\
\text { AR } \\
(\%)\end{array}$ & $\begin{array}{c}D-M \text { for } \\
A R-X \\
v s . \\
A R\end{array}$ & $\begin{array}{c}\text { RMSE of } \\
\text { AR-X } \\
\text { against } \\
\text { VAR } \\
(\%)\end{array}$ & $\begin{array}{c}D-M \text { for } \\
A R-X \\
v s . \\
V A R\end{array}$ & $\begin{array}{c}\text { RMSE of } \\
\text { AR-X } \\
\text { against } \\
\text { AR } \\
(\%)\end{array}$ & $\begin{array}{c}D-M \text { for } \\
A R-X \\
v s . \\
A R\end{array}$ & $\begin{array}{c}\text { RMSE of } \\
\text { AR-X } \\
\text { against } \\
\text { VAR } \\
(\%)\end{array}$ & $\begin{array}{c}D-M \text { for } \\
A R-X \\
v s . \\
V A R\end{array}$ & $\begin{array}{c}\text { RMSE of } \\
\text { AR-X } \\
\text { against } \\
\text { AR } \\
(\%)\end{array}$ & $\begin{array}{c}D-M \text { for } \\
A R-X \\
v s . \\
A R\end{array}$ & $\begin{array}{l}\text { RMSE of } \\
\text { AR-X } \\
\text { against } \\
\text { VAR } \\
(\%)\end{array}$ & $\begin{array}{c}D-M \text { for } \\
A R-X \\
\text { vs. } \\
V A R\end{array}$ \\
\hline $\begin{array}{c}1 \\
3 \\
6 \\
12 \\
24 \\
\end{array}$ & $\begin{array}{c}102.86 \\
104.67 \\
105.82 \\
94.95 \\
100.82 \\
\end{array}$ & $\begin{array}{l}-.49 \\
-1.15 \\
-.77 \\
-1.24 \\
-.18 \\
\end{array}$ & $\begin{array}{c}99.49 \\
103.85 \\
107.69 \\
99.19 \\
101.81 \\
\end{array}$ & $\begin{array}{l}.08 \\
-.95 \\
-1.05 \\
-.21 \\
-.51 \\
\end{array}$ & $\begin{array}{c}107.29 \\
92.72 \\
90.76 \\
95.53 \\
113.67 \\
\end{array}$ & $\begin{array}{c}1.53^{\mathrm{B}} \\
1.18 \\
-1.31^{*} \\
-.66 \\
-1.75^{\mathrm{BB}}\end{array}$ & $\begin{array}{c}100.80 \\
94.90 \\
89.96 \\
91.37 \\
101.46 \\
\end{array}$ & $\begin{array}{c}.14 \\
.89 \\
-1.37^{*} \\
-1.11 \\
-.14\end{array}$ & $\begin{array}{l}155.29 \\
162.14 \\
152.10 \\
158.96 \\
174.10\end{array}$ & $\begin{array}{l}-4.81^{\mathrm{BBB}} \\
-4.60^{\mathrm{BBB}} \\
-3.66^{\mathrm{BBB}} \\
-2.55^{\mathrm{BBB}} \\
-2.42^{\mathrm{BBB}}\end{array}$ & $\begin{array}{l}111.86 \\
155.35 \\
154.46 \\
156.52 \\
158.26 \\
\end{array}$ & $\begin{array}{c}.95 \\
-4.30^{\mathrm{BBB}} \\
-3.96^{\mathrm{BBB}} \\
-2.46^{\mathrm{BBB}} \\
-1.99^{\mathrm{BBB}}\end{array}$ \\
\hline $\begin{array}{c}\text { Period } \\
\text { 1985:8 - 1992:8 } \\
\text { Forecast horizon }\end{array}$ & & & & & & & & & & & & \\
\hline $\begin{array}{c}1 \\
3 \\
6 \\
12 \\
24 \\
\end{array}$ & $\begin{array}{c}105.69 \\
115.54 \\
114.16 \\
92.82 \\
101.58 \\
\end{array}$ & $\begin{array}{l}-.77 \\
-.58 \\
-1.15 \\
-1.14 \\
-.20 \\
\end{array}$ & $\begin{array}{c}102.27 \\
102.23 \\
116.67 \\
99.36 \\
102.53 \\
\end{array}$ & $\begin{array}{c}.40 \\
.40 \\
-1.37^{\mathrm{B}} \\
-.10 \\
-.42 \\
\end{array}$ & $\begin{array}{c}114.31 \\
100.73 \\
85.09 \\
90.43 \\
126.65 \\
\end{array}$ & $\begin{array}{c}-1.80^{\mathrm{BB}} \\
-.07 \\
-1.23 \\
-.98 \\
-2.10^{\mathrm{BB}} \\
\end{array}$ & $\begin{array}{c}111.95 \\
106.33 \\
80.30 \\
80.75 \\
100.23 \\
\end{array}$ & $\begin{array}{c}-1.34^{\mathrm{B}} \\
-.64 \\
-1.57^{*} \\
-1.60^{*} \\
-.01\end{array}$ & $\begin{array}{l}149.45 \\
205.14 \\
198.23 \\
158.18 \\
145.29 \\
\end{array}$ & $\begin{array}{c}-2.31^{\mathrm{BB}} \\
-2.41^{\mathrm{BBB}} \\
-2.31^{\mathrm{BB}} \\
-1.40^{\mathrm{B}} \\
-1.16\end{array}$ & $\begin{array}{l}103.03 \\
162.75 \\
175.60 \\
148.33 \\
127.84\end{array}$ & $\begin{array}{c}-.12 \\
-1.75^{\mathrm{BB}} \\
-2.08^{\mathrm{BB}} \\
1.23 \\
.78\end{array}$ \\
\hline $\begin{array}{c}\text { Period } \\
\text { 1992:9-2007:1 } \\
\text { Forecast horizon }\end{array}$ & & & & & & & & & & & & \\
\hline $\begin{array}{c}1 \\
3 \\
6 \\
12 \\
24\end{array}$ & $\begin{array}{c}99.50 \\
105.81 \\
96.02 \\
97.55 \\
99.50\end{array}$ & $\begin{array}{l}-.05 \\
-1.16 \\
-.50 \\
-.51 \\
-.03\end{array}$ & $\begin{array}{c}96.20 \\
105.20 \\
97.30 \\
98.98 \\
101.09\end{array}$ & $\begin{array}{l}-.40 \\
-1.20 \\
-.36 \\
-.25 \\
-.32\end{array}$ & $\begin{array}{l}101.72 \\
86.20 \\
95.75 \\
100.14 \\
102.10\end{array}$ & $\begin{array}{l}-.31 \\
-1.87^{* *} \\
-.54 \\
-.01 \\
-.23\end{array}$ & $\begin{array}{l}92.62 \\
85.97 \\
99.51 \\
102.36 \\
102.83\end{array}$ & $\begin{array}{l}-1.04 \\
-2.07^{* *} \\
-.08 \\
-.24 \\
-.30\end{array}$ & $\begin{array}{l}158.54 \\
150.18 \\
134.96 \\
159.84 \\
267.60\end{array}$ & $\begin{array}{l}-4.34^{\mathrm{BBB}} \\
-4.13^{\mathrm{BBB}} \\
-3.09^{\mathrm{BBB}} \\
-4.70^{\mathrm{BBB}} \\
-5.55^{\mathrm{BBB}}\end{array}$ & $\begin{array}{l}116.07 \\
140.93 \\
144.94 \\
167.15 \\
269.68\end{array}$ & $\begin{array}{c}-1.21 \\
-4.53^{\mathrm{BBB}} \\
-3.98^{\mathrm{BBB}} \\
-5.14^{\mathrm{BBB}} \\
-5.55^{\mathrm{BBB}}\end{array}$ \\
\hline
\end{tabular}

We report the relative mean squared error statistics against actual future values (in \%) in the first and third columns for each macro variable; values below 100 indicate that the AR-X model containing financial variables is better than the benchmark model (either an AR(2)-representation for the variable in question, or a VAR(2)-system for the vector of all the three macro variables). D-M refers to the Diebold - Mariano (1995)- test statistics for the comparison of the AR-X model to the benchmark models; ***,** and * refer to the cases where the AR-X is better than the benchmark at 1,5 or $10 \%$ significance levels, respectively, whereas BBB, BB, or B to the cases where the corresponding benchmark model is better, respectively. 


\section{Table B2}

Out-of-sample forecast error statistics for Germany and the Euro-zone; unfiltered forecasts

\begin{tabular}{|c|c|c|c|c|c|c|c|c|c|c|c|c|}
\hline & \multicolumn{4}{|c|}{ g; real growth } & \multicolumn{4}{|c|}{$\pi$; inflation rate } & \multicolumn{4}{|c|}{ q: real exchange rate } \\
\hline & RMSE of & $D-M$ for & RMSE of & $D-M$ for & RMSE of & $D-M$ for & RMSE of & $D$-Mfor & RMSE of & $D-M$ for & RMSE of & $D-M$ for \\
\hline & $A R-X$ & $A R-X$ & $A R-X$ & $A R-X$ & $A R-X$ & $A R-X$ & $A R-X$ & $A R-X$ & $A R-X$ & $A R-X$ & $A R-X$ & $A R-X$ \\
\hline Germany & against & $v s$. & against & $v s$ & against & $v s$. & against & $v s$ & against & $v s$. & against & $v s$. \\
\hline 1985:8 - 1990:12 & $A R$ & $A R$ & $V A R$ & $V A R$ & $A R$ & $A R$ & $V A R$ & $V A R$ & $A R$ & $A R$ & VAR & $V A R$ \\
\hline 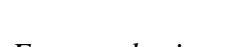 & & & $(\%)$ & & & & (\%) & & $(\%)$ & & (\%) & \\
\hline \multicolumn{13}{|l|}{ Forecast horizon } \\
\hline 1 & 103.58 & -.75 & 98.76 & -.13 & 140.91 & $-1.65^{\mathrm{BB}}$ & 106.90 & -.25 & 301.75 & $-3.63^{\mathrm{BBB}}$ & 147.01 & $-1.75^{\mathrm{BB}}$ \\
\hline 3 & 68.71 & $-4.43^{* * * *}$ & 68.67 & $-3.58^{* * * *}$ & 82.00 & $-1.54^{*}$ & 71.93 & $-1.70^{* * *}$ & 305.30 & $-3.92^{\mathrm{BBB}}$ & 318.63 & $-3.81^{\mathrm{BBB}}$ \\
\hline 6 & 104.35 & -1.21 & 110.35 & $-1.64^{\mathrm{BB}}$ & 90.19 & -.80 & 83.64 & -1.12 & 309.74 & $-4.33^{\mathrm{BBB}}$ & 384.65 & $-4.54^{\mathrm{BBB}}$ \\
\hline 12 & 108.58 & $-1.42^{\mathrm{B}}$ & 110.40 & $-1.48^{\mathrm{B}}$ & 72.41 & $-2.31^{* * *}$ & 73.68 & $-2.02^{* *}$ & 271.58 & $-4.45^{\mathrm{BBB}}$ & 358.05 & $-4.87^{\mathrm{BBB}}$ \\
\hline 24 & 108.85 & -1.25 & 108.88 & -1.09 & 94.23 & -.43 & 102.08 & .21 & 167.51 & $-2.62^{\mathrm{BBB}}$ & 243.58 & $-3.21^{\mathrm{BBB}}$ \\
\hline \multicolumn{13}{|l|}{$\begin{array}{c}\text { Euro-zone } \\
\text { 1998:1 - 2007:11 }\end{array}$} \\
\hline \multicolumn{13}{|l|}{ Forecast horizon } \\
\hline 1 & 106.61 & -.80 & 40.97 & $-5.08^{* * *}$ & 108.09 & $-1.49^{\mathrm{B}}$ & 105.14 & -.75 & 244.44 & $-4.06^{\mathrm{BBB}}$ & 157.14 & $-2.40^{\mathrm{BBB}}$ \\
\hline 3 & 92.16 & $-1.50^{\mathrm{B}}$ & 98.48 & -.28 & 105.83 & -.92 & 106.88 & -1.02 & 342.98 & $-5.08^{\mathrm{BBB}}$ & 253.89 & $-4.19^{\mathrm{BBB}}$ \\
\hline 6 & 101.03 & -.18 & 103.31 & -.64 & 108.94 & $-1.72^{\mathrm{B}}$ & 110.73 & $-2.08^{\mathrm{BB}}$ & 320.64 & $-5.17^{\mathrm{BBB}}$ & 284.15 & $-4.78^{\mathrm{BBB}}$ \\
\hline 12 & 109.20 & -1.07 & 112.61 & $-1.42^{\mathrm{B}}$ & 106.05 & -1.24 & 108.04 & $-1.61^{\mathrm{B}}$ & 306.78 & $-5.53^{\text {ВВВ }}$ & 300.19 & $-5.38^{\mathrm{BBB}}$ \\
\hline 24 & 117.26 & $-1.62^{\mathrm{B}}$ & 119.57 & $-1.67^{\mathrm{BB}}$ & 109.09 & -1.09 & 110.92 & $-1.33^{\mathrm{B}}$ & 416.81 & $-4.31^{\text {BBB }}$ & 407.55 & $-4.32^{\text {BBB }}$ \\
\hline
\end{tabular}

For the notations see Table B1. 
Table B3

Out-of-sample forecast error statistics for Japan; unfiltered forecasts

\begin{tabular}{|c|c|c|c|c|c|c|c|c|c|c|c|c|}
\hline & \multicolumn{4}{|c|}{ g; real growth } & \multicolumn{4}{|c|}{$\pi$; inflation rate } & \multicolumn{4}{|c|}{$q$ : real exchange rate } \\
\hline & $\begin{array}{c}\text { RMSE of } \\
A R-X\end{array}$ & $\begin{array}{c}D-M \text { for } \\
A R-X\end{array}$ & $\begin{array}{c}\text { RMSE of } \\
A R-X\end{array}$ & $\begin{array}{c}D-M \text { for } \\
A R-X\end{array}$ & $\begin{array}{c}\text { RMSE of } \\
A R-X\end{array}$ & $\begin{array}{c}D-M \text { for } \\
A R-X\end{array}$ & $\begin{array}{c}\text { RMSE of } \\
A R-X\end{array}$ & $\begin{array}{c}D-M \text { for } \\
A R-X\end{array}$ & $\begin{array}{c}\text { RMSE of } \\
A R-X\end{array}$ & $\begin{array}{c}D-M \text { for } \\
A R-X\end{array}$ & $\begin{array}{c}\text { RMSE of } \\
A R-X\end{array}$ & $\begin{array}{c}D-M \text { for } \\
A R-X\end{array}$ \\
\hline Period & against & vs. & against & vs. & against & $\begin{array}{c}A \Lambda-\Lambda \\
v s .\end{array}$ & $\begin{array}{c}\text { An-A } \\
\text { against }\end{array}$ & $\begin{array}{c}A \Lambda-\Lambda \\
v s .\end{array}$ & $\begin{array}{c}\text { An-A } \\
\text { against }\end{array}$ & $\begin{array}{c}A \Lambda-\Lambda \\
v s .\end{array}$ & $\begin{array}{c}\text { AN-A } \\
\text { against }\end{array}$ & $\begin{array}{c}A \Lambda-\Lambda \\
v s .\end{array}$ \\
\hline $1985: 8-2007: 1$ & $\begin{array}{l}A R \\
(\%)\end{array}$ & $A R$ & $\begin{array}{r}V A R \\
(\%)\end{array}$ & $V A R$ & $\begin{array}{l}A R \\
(\%)\end{array}$ & $A R$ & $\begin{array}{r}V A R \\
(\%)\end{array}$ & $V A R$ & $\begin{array}{l}A R \\
(\%)\end{array}$ & $A R$ & $\begin{array}{r}V A R \\
(\%)\end{array}$ & $V A R$ \\
\hline \multicolumn{13}{|l|}{ Forecast horizon } \\
\hline 1 & 103.78 & -1.06 & 103.28 & -.73 & 94.79 & -.95 & 94.70 & -.92 & 146.67 & $-2.72^{\mathrm{BBB}}$ & 100.22 & -.02 \\
\hline 3 & 100.91 & -.19 & 102.09 & -.54 & 101.50 & -.30 & 103.24 & -.64 & 179.32 & $-3.36^{\mathrm{BBB}}$ & 152.63 & $-2.53^{\mathrm{BBB}}$ \\
\hline 6 & 103.99 & -.94 & 105.84 & $-1.46^{\mathrm{B}}$ & 103.72 & -.62 & 103.59 & -.63 & 152.87 & $-3.18^{\mathrm{BBB}}$ & 147.63 & $-2.92^{\text {BBB }}$ \\
\hline 12 & 104.73 & -1.17 & 105.88 & $-1.51^{\mathrm{B}}$ & 108.91 & -1.26 & 110.04 & $-1.41^{\mathrm{B}}$ & 111.26 & -.90 & 112.59 & -.99 \\
\hline 24 & 110.36 & $-2.22^{\mathrm{BB}}$ & 112.36 & $-2.39^{\mathrm{BBB}}$ & 115.52 & $-1.53^{\mathrm{B}}$ & 113.05 & $-1.30^{\mathrm{B}}$ & 61.83 & $-1.78^{\text {** }}$ & 63.37 & $-1.81^{\text {*** }}$ \\
\hline \multicolumn{13}{|l|}{$\begin{array}{c}\text { Period } \\
\text { 1985:8 - 1998:12 }\end{array}$} \\
\hline \multicolumn{13}{|l|}{ Forecast horizon } \\
\hline 1 & 102.97 & -.49 & 100.75 & -.14 & 90.91 & $-1.46^{*}$ & 93.36 & -1.00 & 125.50 & $-1.56^{\mathrm{B}}$ & 91.67 & -.56 \\
\hline 3 & 97.07 & -.54 & 98.57 & -.31 & 99.18 & -.14 & 102.54 & -.45 & 125.20 & $-1.70^{\mathrm{B}}$ & 108.14 & -.65 \\
\hline 6 & 100.46 & -.09 & 102.50 & -.49 & 98.10 & -.31 & 98.46 & -.25 & 106.80 & .57 & 105.33 & -.44 \\
\hline 12 & 100.43 & -.09 & 101.63 & -.33 & 107.83 & -.93 & 110.21 & -1.18 & 94.36 & -.42 & 96.96 & -.22 \\
\hline 24 & 104.68 & -.88 & 106.45 & -1.08 & 123.35 & $-1.80^{\mathrm{BB}}$ & 120.99 & $-1.62^{\mathrm{B}}$ & 38.84 & $-2.78^{* * *}$ & 40.11 & $-2.75^{* * *}$ \\
\hline
\end{tabular}

For the notations see Table B1. 